\title{
Interactions Between Mean Sea Level, Tide, Surge, Waves and Flooding: Mechanisms and Contributions to Sea Level Variations at the Coast
}

\author{
Déborah Idier $^{1}$ (D) $\cdot$ Xavier Bertin ${ }^{2} \cdot$ Philip Thompson $^{3} \cdot$ Mark D. Pickering $^{4}$
}

Received: 19 November 2018 / Accepted: 8 June 2019 / Published online: 26 June 2019

(c) The Author(s) 2019

\begin{abstract}
Coastal areas epitomize the notion of 'at-risk' territory in the context of climate change and sea level rise (SLR). Knowledge of the water level changes at the coast resulting from the mean sea level variability, tide, atmospheric surge and wave setup is critical for coastal flooding assessment. This study investigates how coastal water level can be altered by interactions between SLR, tides, storm surges, waves and flooding. The main mechanisms of interaction are identified, mainly by analyzing the shallow water equations. Based on a literature review, the orders of magnitude of these interactions are estimated in different environments. The investigated interactions exhibit a strong spatiotemporal variability. Depending on the type of environments (e.g., morphology, hydrometeorological context), they can reach several tens of centimeters (positive or negative). As a consequence, probabilistic projections of future coastal water levels and flooding should identify whether interaction processes are of leading order, and, where appropriate, projections should account for these interactions through modeling or statistical methods.
\end{abstract}

Keywords Water level · Hydrodynamics · Interaction processes · Implications · Flood · Quantification · Modeling

Déborah Idier

d.idier@brgm.fr

Xavier Bertin

xbertin@univ-lr.fr

Philip Thompson

philiprt@hawaii.edu

Mark D. Pickering

mdp053@gmail.com

1 BRGM, 3 av. C. Guillemin, 45060 Orléans Cédex, France

2 UMR 7266 LIENSs, CNRS - La Rochelle University, 2 rue Olympe de Gouges, 17000 La Rochelle, France

3 Department of Oceanography, University of Hawai 'i at Manoa, 1000 Pope Road, Honolulu, HI 96822, USA

4 University of Southampton, University Road, Southampton SO17 1BJ, UK 


\section{Introduction}

Coastal areas are considered 'at-risk' territories in the context of climate change and sea level rise (SLR). Knowledge of water level variability at the coast, especially the still water level and storm tide, is critical for coastal flooding assessment, both for present and for future climate. Still water level includes mean sea level, tide and atmospheric surge (Fig. 1a). Several definitions can be found for storm tides; here, we consider that they include mean sea level, tide, atmospheric storm surge and wave setup.

According to the IPCC 5th Assessment Report, the likely range of future global mean sea level (GMSL) for the high emissions scenarios is +0.5 to $+1 \mathrm{~m}$ by 2100 (Church et al. 2013b), which does not preclude more extreme scenarios (Church et al. 2013a). Importantly, sea level will continue to rise beyond 2100 (Church et al. 2013b) and is likely to reach several meters by 2200 (Kopp et al. 2014). Such changes in mean sea level will produce significant societal impact.

A widely used approach to account for mean sea level changes in flood hazard assessment is to linearly add the sea level rise to selected still water level scenarios to estimate the flood hazard. Such an approach relies on the underlying assumption that there is no significant nonlinear interaction between contributions to water level variability, such as SLR, tide and surge. However, some studies show evidence that these interactions can represent a significant part of water level changes. For instance, using a numerical modeling approach, focusing on the German Bight area (SE of North Sea) and assuming a sea level rise of $0.54 \mathrm{~m}$, Arns et al. (2015) show that taking into account the interactions between mean sea level, tide and atmospheric surge leads to a 50-year return still water level $12 \mathrm{~cm}$ larger than when these interactions are neglected, corresponding to a doubling of the frequency of 50-year return still water level obtained neglecting the interactions.

The present review focuses on water level resulting from mean sea level, tide and surge (atmospheric surge and wave setup) and investigates how this water level can be altered by interaction processes occurring between SLR, tides, storm surges, waves and flooding. Indeed, many mechanisms can affect the still water level (e.g., changes in seabed morphology, oceanographic circulations, tide-surge interactions, etc.). Figure $1 \mathrm{~b}$ schematizes some

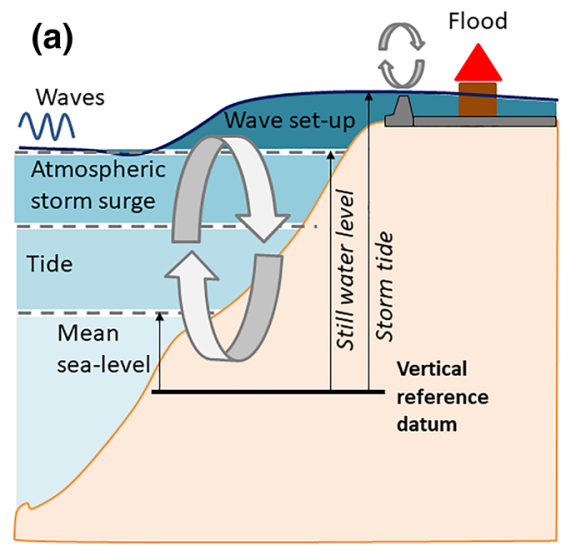

(b)

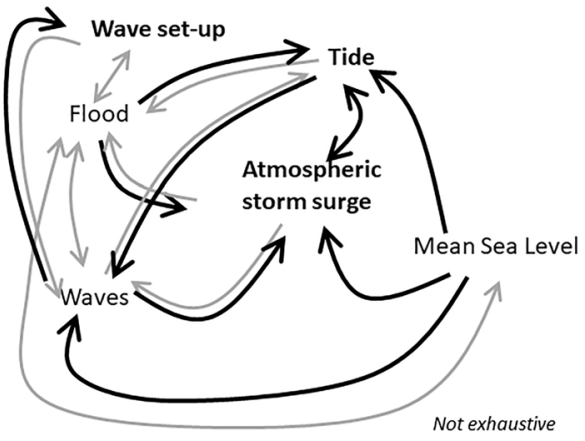

Fig. 1 a Components of storm tide, terminology and sketch of interactions. b Main interactions between mean sea level, waves, atmospheric storm surges, tide, wave setup and flooding. In bold and black: the focus of the present paper 
of these interactions. The main interactions to be investigated in this review are: (1) the SLR effect on tides, atmospheric surges and waves, (2) the tide effect on atmospheric storm surges, waves and wave setup, (3) the flooding effect on tide and still water level (including human adaptation on tides), (4) the effect of short waves on atmospheric surges.

The present paper aims at highlighting these interaction mechanisms and at providing the orders of magnitude of the interactions contributions to the water level at the coast. One of the difficulties is to isolate the influence of each interaction. Observations (e.g., from tide gauges) can provide insights into changes in mean sea level, tides, surge, or even sometimes the wave setup, but, as highlighted by Woodworth (2010) and Haigh et al. (2018), many processes can affect tide changes (SLR, harbor infrastructures, long-term changes in the tidal potential, changes in internal tide, morphological changes, etc.), such that it is difficult to properly isolate the influence of each parameter based on these observations. Thus, the present review is mainly based on modeling studies.

The paper is organized as follows. First, the main mechanisms leading to changes in mean sea level, tidal amplitude, atmospheric surge and wave setup are reviewed together with their orders of magnitude (Sect. 2). Then, each of the interaction mechanisms is described and orders of magnitude are provided in different environments (Sect. 3). Section 4 provides a synthesis and examples of combined interactions, before discussing the limits of the review and the implications for projections of water level at the coast and flood hazard estimation. Remaining questions are also highlighted. Section 5 draws the main conclusions.

\section{Mean Sea Level, Tide, Atmospheric Surge and Wave Setup: Mechanisms and Orders of Magnitude}

What follows is a summary of the main mechanisms or factors leading to changes in mean sea level and leading to tide, atmospheric storm surge and wave setup. Here, mean sea level can be considered as a zeroth-order component (low frequency), while tide, atmospheric surge and wave setup (higher frequency) are considered as first-order components.

As highlighted by Woodworth et al. (2019), mean sea level can be affected by many factors. In addition to long-term trends related to climate change, mean sea level is subject to seasonal variability due to changes in thermal expansion and salinity variations (steric effect), air pressure and winds, land and sea ice melt, oceanographic circulation, river runoff, etc. Some inter-annual and decadal variability can also be observed as a result of the effect of climate modes like El Niño Southern Oscillation (ENSO), North Atlantic Oscillation (NAO) or Pacific Decadal Oscillation (POD) resulting in large-scale sea level change. Fifteen thousand years ago, GMSL was more than $100 \mathrm{~m}$ below present (Clark et al. 2016). According to Church et al. (2013a), GMSL will increase by several tens of centimeters and could exceed $1 \mathrm{~m}$ in 2100 .

Tides are generated by gravitational forces acting over the whole water column in the deep ocean, with a gravitational feedback in tidal dynamics known as self-attraction and loading [SAL, Hendershott (1972)]. In deep water, tides have wavelengths of several hundreds of kilometers, i.e., much longer than the water depth. They propagate as shallow water waves, influenced by the Earth's rotation (Coriolis force), and are dissipated by bottom friction in shallow water on continental shelves and by energy loss to internal tides (Ray 2001). Local or basin-scale enhancements can occur due to resonance producing very large tides (Godin 1993). At the global scale, depending on the location, spring tidal ranges 
vary from a few tens of centimeters to several meters and can locally exceed 10 meters as in the Bay of Fundy (Pugh 1987). The atmospheric storm surges can also be regarded as long waves. They are generated by changes in atmospheric pressure and wind stress acting on the sea surface. Similar to tides, storm surges propagate to the coast as shallow water waves and are subject to seabed friction, Earth's rotation (Coriolis force), and local enhancements due to resonance producing large surges. Atmospheric surge of tens of centimeters and up to $1 \mathrm{~m}$ is frequently observed on the Northwest European shelf (e.g., Brown et al. 2010; Idier et al. 2012; Breilh et al. 2014; Pedreros et al. 2018) and can exceed 2-3 m under specific stormy conditions, such as in the North Sea in 1953 (Wolf and Flather 2005). It should be noted that these values correspond to the so-called practical storm surge, i.e., the difference between the still water level and the tide. In cyclonic environments, pure atmospheric surge (i.e., without accounting for tide-surge interaction) can reach almost $10 \mathrm{~m}$ (e.g., Nott et al. 2014).

In a first approximation, tides and surge can be modeled by the shallow water equations, which can be written as follows, omitting the horizontal viscosity term $\left(A \nabla^{2} u\right)$ for the sake of clarity:

$$
\begin{gathered}
\frac{\partial \xi}{\partial t}+\nabla \cdot(D \cdot \mathbf{u})=0 \\
\frac{\partial \mathbf{u}}{\partial t}+\mathbf{u} \cdot \nabla \mathbf{u}-f \mathbf{k} \cdot \mathbf{u}=-g \nabla \xi+\frac{1}{\rho} \nabla p_{\mathrm{a}}+\frac{\tau_{\mathrm{s}}}{\rho D}-\frac{\tau_{\mathrm{b}}}{\rho D}+\mathbf{F}+\mathbf{\Pi}
\end{gathered}
$$

with $\mathbf{u}$ the depth-integrated current velocity, $\xi$ the free surface, $D$ the total water depth (equal to the sum of undisturbed water depth $H$ and the free surface elevation $\xi$ ), $\rho$ the density of sea water, $g$ the gravitational acceleration, $p_{\mathrm{a}}$ the sea level atmospheric pressure, $f$ the Coriolis parameter ( $2 \omega \sin \phi$, with $\omega$ the angular speed of Earth rotation and $\phi$ the latitude) and $\mathbf{k}$ a unit vector in the vertical. $\tau_{\mathrm{b}}$ and $\tau_{\mathrm{s}}$ are, respectively, the bed and wind shear stress, which can be written as follow (assuming a quadratic law):

$$
\begin{gathered}
\tau_{\mathbf{s}}=\rho_{\mathrm{a}} C_{D_{\mathrm{s}}} \mathbf{U}_{10}\left|\mathbf{U}_{10}\right| \\
\tau_{\mathbf{b}}=C_{D_{\mathrm{b}}} \mathbf{u}|\mathbf{u}|
\end{gathered}
$$

where $C_{D_{\mathrm{s}}}$ and $C_{D_{\mathrm{b}}}$ are the free surface and bottom drag coefficients, respectively, $\rho_{\mathrm{a}}$ is the air density and $\mathbf{U}_{10}$ is the wind velocity at $z=10 \mathrm{~m}$. Finally, $\mathbf{F}$ includes other forces such as the wave-induced forces leading to wave setup, and $\boldsymbol{\Pi}$ includes tide-related forcing terms (e.g., self attracting load, tidal potential forces). In the case of pure tides, the second, third and fifth terms of the right-hand side of Eq. (2) are equal to zero. In the case of pure atmospheric storm surge, the last term is equal to zero. From the equations, it can be readily seen that the effect of wind depends on water depth and increases as the depth decreases, whereas the atmospheric pressure effect is depth independent. In deep water, surge elevations are therefore approximately hydrostatic, while surge production by the wind stress can be large on shallow continental shelves.

In the nearshore, the dissipation of shortwaves through depth-limited breaking (with a small contribution from bottom friction) results in a force that drives currents and wave setup along the coast, which can substantially contribute to storm surges. Under energetic wave conditions, wave setup can even dominate storm surges along coasts bordered by narrow to moderately wide shelves or at volcanic islands (Kennedy et al. 2012; Pedreros et al. 2018). Several studies combining field observations with numerical modeling also 
demonstrated that wave breaking over the ebb shoals of shallow inlets (Malhadas et al. 2009; Dodet et al. 2013) as well as large estuaries (Bertin et al. 2015; Fortunato et al. 2017) results in a setup that can propagate at the scale of the whole backbarrier lagoon or estuary. Local wave setup of several tens of centimeters up to about $1 \mathrm{~m}$ have been observed (Pedreros et al. 2018; Guérin et al. 2018), while regional wave setup can reach values of tens of centimeters (Bertin et al. 2015). This does not imply that larger values could not exist. The first theoretical explanation for the development of wave setup is due to LonguetHiggins and Stewart (1964), who proposed that the divergence of the shortwave momentum flux associated with wave breaking acts as a horizontal pressure force that tilts the water level until an equilibrium is reached with the subsequent barotropic pressure gradient. However, several studies reported that this model could result in a severe underestimation of wave setup along the coast (Raubenheimer et al. 2001; Apotsos et al. 2007), suggesting that other processes may be involved. Apotsos et al. (2007) and Bennis et al. (2012) proposed that bed shear stress associated with the undertow (bed return flow that develops in surf zones) could contribute to wave setup. Recently, Guérin et al. (2018) showed that the depth-varying currents that take place in the surf zone (horizontal and vertical advection and shear of the currents) could contribute to wave setup substantially, particularly when the bottom is steep.

A broader overview of all forcing factors causing sea level changes at the coast and of their orders of magnitude, from sub-daily (seiche, infra-gravity waves) to long-term scales (centuries), is provided by Woodworth et al. (2019), while Dodet et al. (2019) provide a review on wind-generated waves (processes, methods) and their contributions to coastal sea level changes.

\section{Interaction Mechanisms and Orders of Magnitude}

\subsection{Sea Level Rise Effect on Tide and Atmospheric Surge}

\subsubsection{Mechanisms}

Tides behave as shallow water waves and thus are strongly affected by water depth. There are several mechanisms by which mean sea level changes can alter tidal dynamics (Wilmes 2016; Haigh et al. 2018). Here, we focus on the direct effect of SLR on tides. First, large tidal amplitudes and dissipation occur when the tidal forcing frequency lies close to the natural period of an ocean basin or sea (Hendershott 1973). Therefore, increases in water depth due to MSL rise could push a shelf sea or embayment closer to resonance, increasing tidal range (e.g., in the Tagus estuary after the study of Guerreiro et al. (2015)), or away from resonance, reducing tidal range [e.g., in the Western English Channel according to Idier et al. (2017)]. The sensitivity to such water depth change increases as the basin approaches resonance. Second, the greater water depth implies a reduction in the energy dissipation at the bottom (see Eqs. 2,4) and thus contributes to an increase in tidal range (see, e.g., the study of Green (2010) for numerical experiments in real cases). Third, increase in water depth alters the propagation speed of the tidal wave (and thus causes a spatial reorganization of the amphidrome). For instance, in a semi-enclosed basin and neglecting the dissipation terms, sea level rise causes the amphidromic point to shift toward the open boundary after the analytical solution of Taylor (1922). 
In case of SLR, as for the tides, storm surges are affected by the bottom friction reduction which tends to increase storm surges. However, as illustrated by Arns et al. (2017) in the North Sea, the decreased bottom friction appears to be counteracted by the lessened effectiveness of surface wind stress. Indeed, the same wind forcing (surface stress) is less effective at dragging water and produces a smaller surge when water depth is larger (see the wind forcing term in Eq. 2). Finally, as a counterbalancing effect, SLR will also result, in some locations, in new flooded areas, which will act as additional dissipative areas for tide and surge. In the present section, for the sake of clarity, we do not consider the effect of these additional wet areas. The effect of flooding on tides and on still water level is discussed in Sects. 3.3 and 4.2, respectively.

\subsubsection{Orders of Magnitude}

The SLR effect on tides has been investigated at different scales (global, regional, local) and in different environments. The locations of the main studies presented below are indicated in Fig. 2 (in black). The values given in the next paragraphs correspond to changes in the tidal component alone (i.e., relative to the mean sea level) and not to the absolute tide level (which includes the mean sea level and thus SLR itself). In addition, the orders of magnitude provided below are extracted from model results obtained assuming a fixed shoreline (i.e., impermeable walls along the present-day shoreline).

First, at the global scale, tide response (M2 amplitude or mean high water level for instance) to SLR is widespread globally with spatially coherent non-uniform amplitude changes of both signs in many shelf seas, even considering uniform SLR (Green 2010;

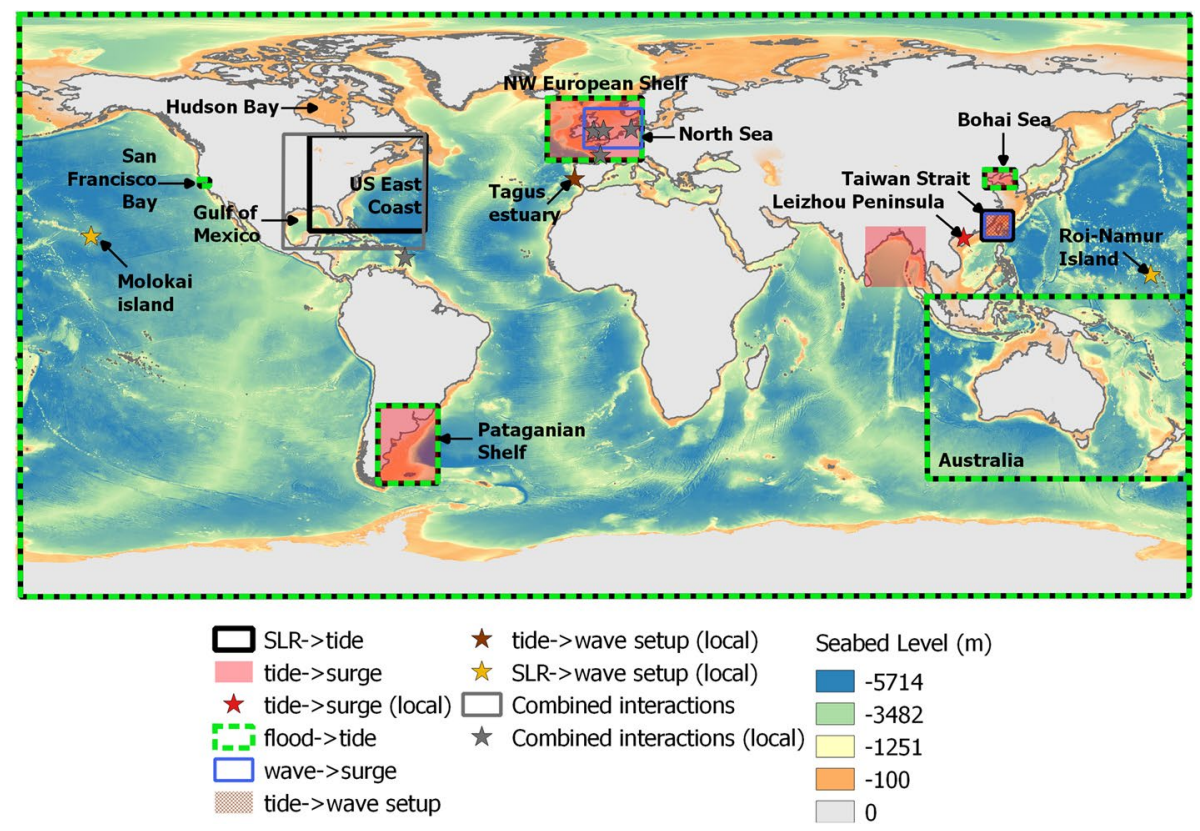

Fig. 2 Global bathymetry [seabed level (m), from The General Bathymetric Chart of the Oceans, GEBCO] and areas investigated in the papers selected to provide orders of magnitude of each of the interactions described in the present review. Stars correspond to very local studies 
Pickering et al. 2017; Schindelegger et al. 2018). Response in the open ocean, where the relative depth change with SLR is small, is generally of a smaller magnitude but with a much greater horizontal length scale. Pickering et al. (2017), focusing on 136 cities of population larger than 1 million (in 2005), assuming fixed shorelines and a uniform SLR of $2 \mathrm{~m}$, found changes in the mean high waters (MHW) varying from -0.25 (Surabaya, Indonesia) to $+0.33 \mathrm{~m}$ (Rangoon, Myanmar) (Fig. 3b). The comparison of bathymetry (here The General Bathymetric Chart of the Oceans, GEBCO, Fig. 2) with the SLR-induced tide changes map of Pickering et al. (2017) (Fig. 2a therein, or Fig. $3 b$ in the present paper) illustrates that along open coasts with narrow continental shelf, the SLR effect on tide appears negligible. In that study, they also investigated the effect of a spatially varying SLR, focusing on fingerprints of the initial elastic response to ice mass loss. These SLR perturbations weakly alter the tidal response with the largest differences being found at high latitudes (see the cumulative distribution of MHW changes for the 136 cities and for the assumption of a fixed shoreline, Fig. 3a).

Focusing on the NW European Shelf (spring tidal range varying from a few centimeters to more than $10 \mathrm{~m}$, mainly in the Bay of Mont Saint Michel), Idier et al. (2017), Pickering et al. (2012) and Pelling et al. (2013a) show that for SLR $=+2 \mathrm{~m}$ and under a 'no flood' assumption (also called fixed shoreline), the $M 2$ amplitude changes up to $\pm 10-15 \%$ of SLR. In terms of high tide changes, Idier et al. (2017) show
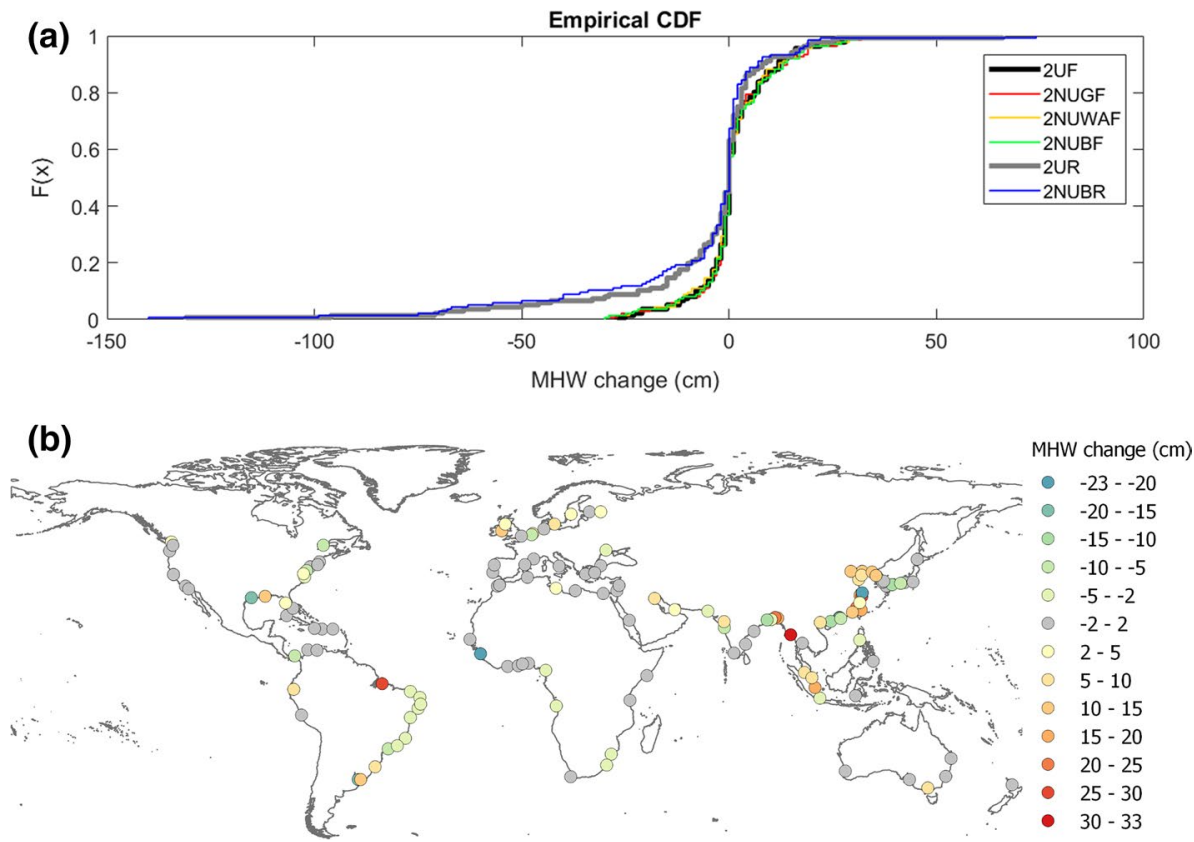

Fig. 3 Mean high water changes in the 136 cities of population larger than 1 million (in 2005) investigated by Pickering et al. (2017). a Empirical cumulative distribution for various SLR scenarios characterized by a global mean SLR of + 2 m: case of a fixed shoreline ('no flood') with a uniform SLR (2UF) or non-uniform SLR corresponding to the initial elastic response of ice sheet melt in Greenland (2NUGF), Western Antarctica (2NUWAF), or both (2NUBF); case with recession ('flood') with a uniform SLR (2UR) or non-uniform SLR corresponding to the initial elastic response of ice sheet melt in Greenland and Western Antarctica (2NUBR). b MHW change for the SLR scenario 2UF. Figures produced here based on the data provided in the supplementary material (Pickering et al. 2017) 
that, depending on the location, changes in the highest tide of the year (in that study: 2009) range from -15 to $+15 \%$ of SLR, i.e., several centimeters to about $15 \mathrm{~cm}$ for $\mathrm{SLR}=1 \mathrm{~m}$. They also show that, when it is assumed that land areas are protected from flooding, the tide components and the maximum tidal water levels vary proportionally to SLR over most of the domain, up to at least SLR $=+2 \mathrm{~m}$. Some areas show nonproportional behavior (e.g., the Celtic Sea and the German Bight). Consistently with the studies of Pelling et al. (2013a) and Pickering et al. (2017), the high tide level decreases in the western English Channel and increases in the Irish Sea, the southern part of the North Sea and the German Bight. The overall agreement between the different modeling experiments is fairly remarkable. Even using different tidal boundary conditions, different spatial resolutions, different models (even if all based on the shallow water equations), Idier et al. (2017), Pickering et al. (2012) and Pelling et al. (2013a) provide similar results in terms of $M 2$ changes (see Figs. 3, 4, 6d in these studies, respectively). These studies agree on a decrease in the western English Channel and in the SW North Sea, and an increase in the eastern English Channel, the central part of the North Sea, the German Bight and the Irish Sea. The main discrepancy is the positive trend along the Danish coast given in Pickering et al. (2012), probably due to the closed model boundary to the Baltic Sea in that study. As an additional comparison, we can also refer to the study of Palmer et al. (2018), which shows strikingly similar spatial patterns of increase and decrease to the one of Pickering et al. (2012), except for the region that spreads out from the Bristol Channel. For a more detailed comparison on the modeling studies of the SLR effect on tides over the European shelf, see Idier et al. (2017).

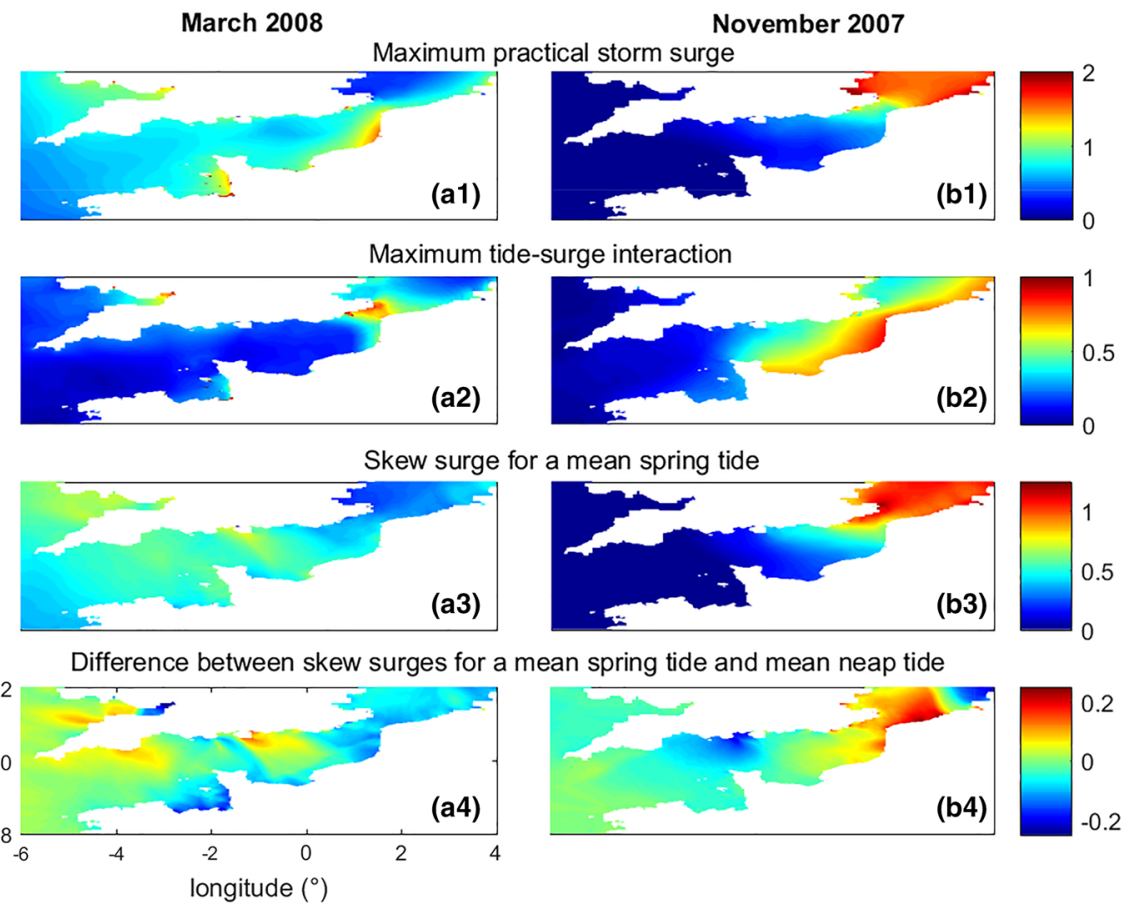

Fig. 4 Tide-surge interactions (in m) for the storms of the March 10-11, 2008, and November 9-10, 2007, in the English Channel, after the study of Idier et al. (2012) 
Other regions have been investigated, such as the Taiwan Strait, which is a long ( $>300$ $\mathrm{km})$ and wide $(\sim 140 \mathrm{~km})$ shelf channel characterized by a mean tidal range varying from less than $1 \mathrm{~m}$ in the southeast end to more than $4 \mathrm{~m}$ in its northwest end. After Kuang et al. (2017), a SLR of $2 \mathrm{~m}$ induces an increase of 1-4 cm for $M 2$ tidal component amplitude and $1 \mathrm{~cm}$ for K1 amplitude. For this area, the global study of Pickering et al. (2017) indicates even larger changes, with an increase of $17 \mathrm{~cm}$ of $M 2$ amplitude at Xiamen (city located on the Chinese coast) and an increase in the maximal tidal range of $36 \mathrm{~cm}$ (for the same SLR of $2 \mathrm{~m}$, assuming fixed present-day coastline).

The SLR effect on tides has also been investigated in the Bohai Sea (China, north of the Taiwan Strait, Fig. 2). For a 'no flood' case and SLR $=2 \mathrm{~m}$, Pelling et al. (2013b) estimated $M 2$ amplitude changes ranging from about -0.1 to $+0.1 \mathrm{~m}$. In addition, the effect of the sea level rise on $M 2$ amplitude in this area is not proportional to the SLR amount.

In the Southern Hemisphere, along the coast of Australia, Harker et al. (2019) found $M 2$ amplitude changes ranging from -0.1 to $+0.1 \mathrm{~m}$ for a SLR of $1 \mathrm{~m}$ with amplitude changes that are not proportional to the SLR in this area, even if the patterns appear similar (in terms of areas of increase or decrease in $M 2$ amplitude).

The effect of SLR on tides in the San Francisco Bay has also been investigated. This bay is characterized by an inlet (width of about $2.5 \mathrm{~km}$ ) and two main bays (one to South, one to the North) of tens of kilometers length and widths varying from few kilometers up to almost $20 \mathrm{~km}$. The mean tidal range varies from 1.8 to about $2.7 \mathrm{~m}$, after the tide data provided by NOAA. With scenarios of hardened shoreline and a SLR of $1 \mathrm{~m}$, the high tide exhibits an increase of $6 \mathrm{~cm}$ and $5 \mathrm{~cm}$ in the southern and northern bay, respectively, i.e., more than $10 \%$ of the natural tide amplification in these bays (Holleman and Stacey 2014).

Regarding the US East coast, the $M 2$ amplitudes range from about 0.4-1.5 m (values extracted from the FES2014 ${ }^{1}$ tidal components database; Carrere et al. 2015). Ross et al. (2017) show that for SLR $=1 \mathrm{~m}$, more than half of the Delaware Bay is projected to experience an $M 2$ amplitude increase of at least $15 \mathrm{~cm}$, while the Chesapeake Bay exhibits a small decrease at the mouth $(-2 \mathrm{~cm})$, and an increase over most of the bay up to $10 \mathrm{~cm}$ at the head. It is also highlighted that changes are proportional to the SLR (especially for SLR $=[-1 ;+1] \mathrm{m})$.

Along the Patagonian Shelf (spring tidal range between 0 and $3 \mathrm{~m}$ ), Carless et al. (2016) show that for SLR $=1 \mathrm{~m}, M 2$ amplitude changes range between -0.1 and $+0.1 \mathrm{~m}$ ("no flood' scenario).

All these studies converge to highlight that the effect of metric SLR can lead to tide changes ( $M 2$ component or spring high tide) up to $\pm 10-15 \%$ of SLR. We could not identify any studies focusing on the sole effect of SLR on atmospheric surge. However, several studies investigated the effect of SLR on still water level or practical storm surge. These studies implicitly take into account not only the effect of SLR on atmospheric surge but also on tides and the tide-surge interactions. The changes induced by these combined interactions are discussed in Sect. 4.2.

\subsection{Tide Effect on Surge}

The present subsection focuses on the effect of tide on surge. However, it should be kept in mind that this is a matter of point of view, and that strictly speaking the mechanisms

\footnotetext{
${ }^{1}$ Finite Element Solution 2014
} 
can be referred to as tide-surge interactions. In addition, we focus on the practical storm surge (also called residual), which is the difference between the still water level and the tide level, such that it includes both the pure atmospheric storm surge and the effect of the tide on the surge.

\subsubsection{Mechanisms}

From Eqs. 1-4, it can be readily seen that there are several nonlinear terms of tide-surge interaction which can be classified in three nonlinear effects:

- the advective effect arising from the advective terms of the momentum Eq. (2).

- the shallow water effect, which arises from nonlinearity related to $D=(H+\xi)$ in Eqs. (1)-(3) in the following terms: advective term of the continuity equation, division by the depth $D$ for the bed friction and wind forcing.

- the nonlinear effect of the bottom friction term with the quadratic parametrization in Eq. (4).

Thus, tidal current and tidal water level interact directly with the hydrodynamics induced by wind and pressure through the advection term, the shallow water effect and the nonlinear friction term related to velocity interactions (Flather 2001; Zhang et al. 2010). The advective term implies that, everything else being equal, the tide-surge interaction is larger for larger tidal currents, such that areas of strong tidal currents are potential areas of strong tide-surge interactions. Regarding the shallow water effect, it contributes to the modulated surge production. Indeed, under some assumptions (mainly 1-D flow and constant wind field) Pugh (1987) shows that the sea surface slope $(\partial \xi / \partial x)$ is in equilibrium with $C_{D_{\mathrm{s}}} U_{10}^{2} /(g D)$, such that the wind stress produces more surge in shallow water, leading to more surge at low tide than at high tide with other factors being equal. As explained by Horsburgh and Wilson (2007), such phenomena can lead to an increase in the phase lag of the practical storm surge compared to the tide, such that the storm surge can precede high water by more than $4 \mathrm{~h}$. Regarding the nonlinear friction term, it appears to be the dominant term in tide-surge interaction in shallow water areas of strong tidal currents (Zhang et al. 2010; Idier et al. 2012). Wolf (1978) investigated the contribution of this nonlinear friction term to the tide-surge interaction. In that study, the definition was slightly different with the quadratic friction term including the water depth variations, i.e., one part of the shallow water effect. They solved analytically the motion equation of two plane progressive waves traveling together in a semi-infinite uniform channel and show that the increase in the interaction on rising tide is due to shallow water and advection effect, whereas the quadratic friction effect tends to reduce it at high tide. Besides, from Eq. (2), the increased force of bed stress due to the alignment of tidal and storm-induced current is offset by the pressure gradient force (surface slope) and then the surge residual, such that tide-surge interaction is intensified in cases of strong alignment of tide and storm surges. From the tide perspective, it should be noted that a positive storm surge (leading to a larger water depth) induces a faster propagating tide (see, e.g., Flather 2001).

\subsubsection{Orders of Magnitude}

The locations of the main studies presented below are indicated in Fig. 2 (in red). At the scale of the NW European shelf, Horsburgh and Wilson (2007) show that, for the storm of 
January 29-30, 2000, tide modified the instantaneous surge of several tens of centimeters (exceeding $50 \mathrm{~cm}$ of changes at high tide for instance in the German Bight). Their analysis of results from selected locations along the East coast of the UK shows changes in the surge peak of tens of centimeters. Focusing on the English Channel, Idier et al. (2012) made surge computations with and without tide using a shallow water model (Fig. 4). For the two selected events (the November 2007 North Sea and March 2008 Atlantic storms), the instantaneous tide-surge interaction is seen to be non-negligible in the eastern half of the English Channel, reaching values of $74 \mathrm{~cm}$ (i.e., $50 \%$ of the same event's maximal storm surge) in the Dover Strait. Using the same hydrodynamic model, simple computations are performed with the same meteorological forcing while varying the tidal amplitude. Skew surges (defined as the difference between the maximum still water level and the maximum predicted tidal level regardless of their timing during the tidal cycle) appear to be tide-dependent, with negligible values $(<0.05 \mathrm{~m})$ over a large portion of the English Channel, but reaching several tens of centimeters in some locations (e.g., the Isle of Wight and Dover Strait).

The Bay of Bengal is another region where tide-surge interactions are known to be very relevant (Johns et al. 1985). Krien et al. (2017b) performed numerical experiments during cyclone Sidr (2007), focusing on the head of the bay. They investigated the interaction between the tide and the total storm surge (including wave setup). As the computed wave setup ranged from 0.2 to $0.3 \mathrm{~m}$ and varies little over a tidal cycle, the tide-surge interactions analyzed by these authors mostly correspond to the effect of the tide on atmospheric surge and vice versa. They showed that tide-surge interactions in the range $\pm 0.6 \mathrm{~m}$ develop in shallow areas of this large deltaic zone. In addition, such interactions occurred at a maximum of 1-2 h after low tide due to the combination of a stronger wind contribution during periods of shallow depth and a faster propagating tide compared to a situation without surge. These findings corroborate those of Johns et al. (1985), Antony and Unnikrishnan (2013) and Hussain and Tajima (2017).

The Taiwan Strait is one example where the pattern of strong tidal currents and storminduced currents along the channel direction enhances tide-surge interaction via nonlinear bottom friction (Zhang et al. 2010). This strait is subject to large storm surges frequently occurring during the typhoon season; from 1949 to 1990 there were 69 typhoons inducing storm surges over $1 \mathrm{~m}$ along at the western bank of the Taiwan Strait (Fujian coast), including four with storm surge larger than $2 \mathrm{~m}$. Oscillations of about $0.4 \mathrm{~m}$ have been observed at tide gauges along the northern Fujian coast, the west bank of the Taiwan Strait, during Typhoon Dan (1999) (for this event, surge ranged from $0.6 \mathrm{~m}$ to more than $1 \mathrm{~m}$ at the tide gauges). The numerical experiments of Zhang et al. (2010) show that these oscillations are due to tide-surge interaction.

At the East of the Taiwan strait, tide-surge interactions have been investigated along the coast of the Leizhou Peninsula (LP) by Zhang et al. (2017) (Fig. 2). This area is characterized by extensive mudflats, large tidal ranges and a complex coastline. The largest amplitudes of tide-surge interaction are found in the shallow water region of the Leizhou Bay, with values up to $1 \mathrm{~m}$ during typhoon events. Numerical experiments reveal that nonlinear bottom friction is the main contributor to tide-surge interaction in this area.

Further east, the effect of tide on surge has been investigated in the Bohai Sea and the East China Sea. Xu et al. (2016) selected one typhoon, assumed that this typhoon arrives at 12 different times (the other conditions remaining constant) and analyzed the results in four tidal stations. The modeled storm surge elevations exhibit wide variations across the twelve cases, reaching differences up to $58 \mathrm{~cm}$ (at Yingkou tidal station). 
Tide-surge interactions have also been investigated on the Patagonian Shelf. Etala (2009) found differences of tens of centimeters at the head of the bay and mouth of Rio de la Plata (Brazil).

The above studies converge to highlight that tide-surge interactions can produce tens of centimeters of water level at the coast with up to $1 \mathrm{~m}$ contributions in some cases.

\subsection{Flooding Effect on Tide}

\subsubsection{Mechanisms}

In Sects. 3.1 and 3.2, we considered that the shoreline was fixed. In other words, we assume that the coastal defenses (natural or man-made) are high enough to protect the lands from the flood. Removing this assumption can lead locally to more space for water, especially adding very shallow areas, i.e., areas of additional energy dissipation. Such effect can balance for instance the pure effect of SLR on tides. At the global scale, Pickering et al. (2017) investigated the impact of flood defenses and SLR on the tidal regime: SLR scenarios allowing for coastal recession (i.e., allowing for flood) tend increasingly to result in a reduction in tidal range. At this global scale, according to Pickering et al. (2017), the fact that the fixed and recession shoreline scenarios result mainly in changes of opposing sign is explained by the effect of the perturbations on the natural period of oscillation in the basin. At a regional scale, the effect of allowing dry land to flood is more complex. For instance, Pelling et al. (2013a) show that the North Sea is dominated by the flooding of the Dutch coast which shifts the areas of tidal energy dissipation from the present coastline to the new cells and thus moves the amphidromic points toward the coast.

\subsubsection{Orders of Magnitude}

The locations of the main studies presented below are indicated in green in Fig. 2. As in Sect. 3.1, the values given in the next paragraphs correspond to changes in the sole tidal component (i.e., relative to the mean sea level).

At the global scale, according to Pickering et al. (2017), assuming a receding shoreline except around Antarctica and a SLR of $2 \mathrm{~m}$ tends to result in a reduction in the tidal range, with more cities exhibiting mean high water reduction. For instance, Rotterdam (the Netherlands) experiences a change of $-0.69 \mathrm{~m}$ in MHW compared to the present-day MHW of $1.31 \mathrm{~m}$. Changes occur at the coast but also in the open ocean, highlighting that the flood effect is not only local. In that study, tide changes appear more sensitive to the shoreline evolution (recession or fixed), than to the non-uniformity of SLR (Fig. 3a). Comparing the $M 2$ amplitude changes of Schindelegger et al. (2018) with the ones of Pickering et al. (2017), $M 2$ appears less sensitive to flooding in the former study. However, it should be kept in mind that these global modeling studies are run at a scale of $1 / 12^{\circ}$ and $1 / 8^{\circ}$, respectively.

On the NW European shelf, comparing 'flood' and 'no flood' scenarios, Pelling et al. (2013a) found $M 2$ amplitude changes up to more than $10 \mathrm{~cm}$ (for SLR $=2 \mathrm{~m}$ ), especially along the German and Danish coasts. From a quantitative point of view, the numerical experiment of Idier et al. (2017) shows that the sign of high-tide level changes obtained for the 'flood' and 'no flood' scenarios is the same across most of the NW European shelf area (57\% of the computational domain). Significant local changes are observed especially along the German and Danish coasts (see, e.g., point $\mathrm{C}$ of Fig. 5). As highlighted by 
Fig. 5 Changes in maximum annual high tide (2009) versus SLR for points A (Mont Saint Michel Bay) and C (German Bight), for the 'no flood' and 'flood' scenarios, after the study of Idier et al. (2017)

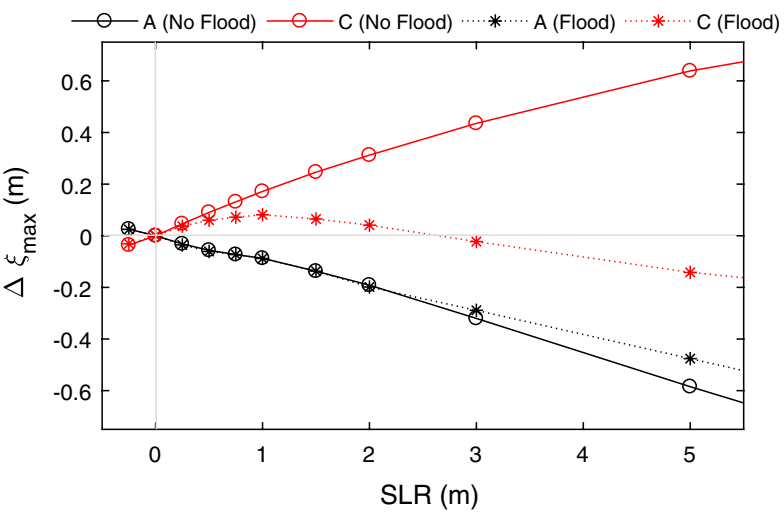

Pelling et al. (2013a), local flooding can have an effect at the basin scale: the flooding of the low-lying Dutch coast is the main forcing for the response of the M2 amplitude to SLR seen in the North Sea. It should be noted that there is a strong consistency between these modeling studies. Idier et al. (2017) and Pelling and Green (2014) provide very similar M2 amplitude changes in terms of order of magnitude and patterns. The main discrepancy is in the Bristol Channel, which may be due to the differences in spatial resolution and quality of the topographic data used in each case.

In San Francisco Bay, Holleman and Stacey (2014) and Wang et al. (2017) also investigated the effect of coastal defense scenarios. We discussed in Sect. 3.1 that a SLR of $1 \mathrm{~m}$ induces an increase of 6 and $5 \mathrm{~cm}$ in the southern and northern bay in the case of hardened shoreline scenario based on the study of Holleman and Stacey (2014). These authors made the same experiment with present coastal defenses and topography, finding a decrease in the high tide level (relative to the mean sea level) ranging from a few centimeters to $13 \mathrm{~cm}$, i.e., an opposite change compared to results obtained with the hardened shoreline scenarios. Wang et al. (2017) also investigated the effect of coastal defenses on tides, considering two scenarios: existing topography and full-bay containment that follows the existing land boundary with an impermeable wall. Comparing the model results obtained for both scenarios, they found that the semidiurnal mode exhibits local changes at the shoreline up to $2 \mathrm{~mm}$, changes in the diurnal mode extend into the bay (reaching values of about $1 \mathrm{~mm}$ ), and overtide changes exhibit a significant spatial variability (with changes exceeding locally $2 \mathrm{~mm}$ ). But the most important impact of the full-bay containment appears to be in the long-term process, with the changes in the long-term tidal mode being almost uniform in space, and exceeding $5 \mathrm{~mm}$.

Along the coast of Australia, Harker et al. (2019) found that the effect of coastal defense on $M 2$ and $\mathrm{K} 1$ amplitude is very small for a SLR of $1 \mathrm{~m}$, with changes smaller than $1 \mathrm{~cm}$. As stated by the authors, this is likely due to the fact that allowing land to flood only increases the wetted area by few cells for this SLR scenario. For a larger SLR $(7 \mathrm{~m})$, the effect of allowing dry land to flood is much larger with changes ranging between $-20 \mathrm{~cm}$ and $+20 \mathrm{~cm}$.

On the Patagonian Shelf, Carless et al. (2016) show that allowing model cells to flood leads to $M 2$ amplitude changes larger than in the case of a fixed shoreline, with more negative changes in the 'flood' scenario, but also that the sign of changes can be locally reversed. The absolute difference of $M 2$ amplitude changes between the 'flood' and 'no flood' scenarios can locally exceed $15 \mathrm{~cm}$ for SLR $=1 \mathrm{~m}$ (Fig. 5). 
The above studies show that, when previously dry land is allowed to flood, it can decrease the amplitude of high tide by a few or even tens of centimeters relative to the case where flooding is prevented. A key point is that initially flood defense schemes have localized benefits (they defend the coast line they protect). However, as shown for instance by Pelling and Green (2014), the process of flooding or not can have an impact on tides at the entire basin scale (e.g., North Sea).

\subsection{Wave Effect on Atmospheric Storm Surges}

\subsubsection{Shear Stress at the Sea Surface}

For a long time, the drag coefficient $C_{D_{\mathrm{s}}}$ used to compute the surface stress due to wind (see Eq. 3) was assumed to increase linearly with wind speed. Although such a simple approach appears attractive for implementation in storm surge models, it has several major shortcomings. First, several studies relying on field and laboratory measurements suggested that under extreme winds the sea surface roughness — and therefore the drag coefficient—could plateau after $30 \mathrm{~m} / \mathrm{s}$ and even decrease for higher winds (e.g., Powell et al. 2003). This behavior was attributed to the development of wave-induced streaks of foam and sprays, which tend to smooth the sea surface. Second, for a given wind speed, significant scatter exists and $C_{D_{\mathrm{s}}}$ could vary by $30 \%$ or more. This scatter was partly explained by the fact that the sea surface roughness does not only depend on the wind speed but also depend on the sea state. Following the pioneering work of Van Dorn (1953) and Charnock (1955), Stewart (1974) proposed that, for a given wind speed, the sea surface roughness should also depend on the wave age, which is defined as the ratio between the shortwave velocity and the friction velocity. Using a coupled wave and storm surge model, Mastenbroek et al. (1993) showed that using a wave-dependent surface stress could increase the surface stress by $20 \%$ while better matching the observations. Performing a numerical hindcast of the February 1989 storm in the North Sea, they showed that using a wave-dependent drag parameterization rather than the ones of Smith and Banke (1975) (quadratic wind shear stress with $\left.C_{D_{\mathrm{s}}}=f\left(U_{10}\right)\right)$ leads to an increase of $20 \mathrm{~cm}$ for the modeled highest water level reached during the storm. In the Taiwan Strait, Zhang and Li (1996) show that the wave effect on atmospheric storm surges is significant, reaching about $20 \mathrm{~cm}$ for the typhoon Ellen (September 1983, $297 \mathrm{~km} / \mathrm{h}$ gusts) and for an observed surge peak of almost $1 \mathrm{~m}$. The dependence of the surface stress to the sea state was then corroborated in many studies (Moon et al. 2004, 2009; Bertin et al. 2012, 2015). In particular, Bertin et al. (2015) performed a high-resolution hindcast of the storm surge associated with the Xynthia (2010) storm in the Bay of Biscay and showed that the young sea state associated with this storm increased the surface stress by a factor of two. More precisely, they compared the surges obtained with quadratic formulation to the ones obtained with wave-dependent parameterization to compute wind stress. They found that both approaches perform similarly except during the storm peak, where the surge with the wave-dependent parameterization for wind stress is $30 \%$ larger, i.e., several tens of centimeters larger, bringing the model results closer to the observations. All these studies show that the wave effect on the sea surface roughness can lead to increases in storm surge of a few centimeters up to tens of centimeters. 


\subsubsection{Shear Stress at the Seabed}

In coastal zones, the near-bottom orbital velocities associated with the propagation of short waves become large and enhance bottom stress (Grant and Madsen 1979). Several studies investigated the impact of wave-enhanced bottom stress on storm surges (Xie et al. 2003; Nicolle et al. 2009) although it is not really clear whether accounting for this process improves storm surge predictions or not (Jones and Davies 1998). Bertin et al. (2015) argued that, most of the time, the tide gauges used to validate storm surge models are located in harbors connected to deep navigation channels, where bottom friction is rather a second-order process and affect storm surges by less than $0.1 \mathrm{~m}$. Further research is needed, including field measurements in shallow water.

\subsection{Tide Effect on Waves and Wave Setup}

\subsubsection{Mechanisms}

In the nearshore, tides can have a significant effect on short waves. First, tide-induced water level variations shift the cross-shore position of the surf zone, so that wave heights are modulated along a tidal cycle (Brown et al. 2013; Dodet et al. 2013; Guérin et al. 2018). Second, in coastal zones subjected to strong tidal currents such as estuaries and tidal inlets, tidal currents can substantially affect the wave field (Ardhuin et al. 2012; Rusu et al. 2011; Dodet et al. 2013). Neglecting dissipation, the conservation of the shortwave energy flux implies that, during the flood phase, waves following currents decrease while, during the ebb phase, waves propagating against currents increase (Dodet et al. 2013; Bertin and Olabarrieta 2016). However, during this ebb phase, as and when currents increase, the increase in wave height together with the decrease in wavelength increases the wave steepness. This increase in steepness can induce dissipation by whitecapping, although this process affects mostly higher frequencies (Chawla and Kirby 2002; Dodet et al. 2013; Bertin and Olabarrieta 2016; Zippel and Thomson 2015). In very shallow inlets and estuaries, tidal currents can also reach the group speed of the short waves so that full blocking can eventually occur (Dodet et al. 2013; Bertin and Olabarrieta 2016). As a consequence of wave setup being controlled mainly by the spatial rate of dissipation of short waves, wave setup along the shoreline or inside estuaries can exhibit large tidal modulations. Such modulation is illustrated by Dodet et al. (2013) and Fortunato et al. (2017) for the case of inlets; they show that wave breaking is more intense on ebb shoals at low tide so that the associated setup in the lagoon/estuary is higher at low tide.

\subsubsection{Orders of Magnitude}

In the Taiwan Strait, the numerical experiment of Yu et al. (2017) for Typhoon Morakot (2009) shows that an increase in significant wave height $\left(H_{\mathrm{s}}\right)$ of about $0.5 \mathrm{~m}$ occurred at Sansha (China coast) during high water levels induced by tidal change and atmospheric storm surge. The $H_{\mathrm{s}}$ difference at other estuary regions is also significant with a range of $-0.4 \mathrm{~m}$ at low water levels and $0.4 \mathrm{~m}$ at high water levels. In locations with larger currents or depths, $H_{\mathrm{s}}$ appear less correlated with water level variations. From the results of the numerical experiments, a weak modulation of the wave setup is observed (up to about 2 $\mathrm{cm}$, based on Fig. 8 therein) for $H_{\mathrm{s}}$ of about 2-3 m. 
Along the French Atlantic Coast (Truc Vert beach) during storm Johanna (March 10), Pedreros et al. (2018) estimated wave setup modulations of tens of centimeters, sometimes exceeding $40 \mathrm{~cm}$. These modulations were found at a given nearshore location, i.e., a fixed point located in the surf zone. At the waterline, the modulation is found to be much weaker (few centimeters).

Fortunato et al. (2017) performed a high-resolution hindcast of the storm surge associated with the 1941 storm in the Tagus Estuary (Portugal, Fig. 2), which corresponds to the most damaging event to strike this region over the last century. Their numerical results suggest that the significant wave height of incident waves exceeded $10 \mathrm{~m}$ and dissipation of the waves on the ebb shoal resulted in the development of a wave setup reaching up to $0.35 \mathrm{~m}$ at the scale of the whole estuary. This setup was tidally modulated and ranged from 0.10 to $0.15 \mathrm{~m}$ at high tide (when dissipation was lowest) and $0.30-0.37 \mathrm{~m}$ at low tide. In addition, Fortunato et al. (2017) revealed a more subtle mechanism, where wave setup is also amplified along the estuary up to $25 \%$ through a resonant process.

\subsection{Sea Level Rise Effect on Waves and Wave Setup}

The impact of SLR on waves and wave setup is difficult to evaluate at sandy beaches. On the one hand, assuming an unchanged bathymetry (i.e., no morphological adaptation to SLR) and considering that the bottom slope increases along the beach profile (i.e., Dean 1991), SLR would imply that waves would break over a steeper bottom, which would result in an increase in wave setup. On the other hand, it is more likely that the beach profile will translate onshore due to SLR (Bruun 1962), so that wave setup would be globally unchanged. Due to large uncertainties concerning the response of sandy coastlines to SLR, we focus the review on studies investigating the effect of SLR on reef environment, assuming that the reef will weakly change for metric SLR.

Quataert et al. (2015) investigated this effect on Roi-Namur Island (Marshall Islands, Fig. 2), showing that an offshore water level increase (e.g., SLR) leads to a decrease in wave setup on the reef. According to their computations, a SLR of $1 \mathrm{~m}$ leads to a wave setup decrease in tens up to $50 \mathrm{~cm}$ (for $H_{\mathrm{s}}=3.9 \mathrm{~m}$ and $T_{p}=14 \mathrm{~s}$ ). They also show that these changes are increased by narrow reef and steep fore reef slope. On the Molokai coral reefs (Hawaii), Storlazzi et al. (2011) show that the SLR effect on wave height and wave setup leads to changes in total water level (relative to SLR) of a few centimeters for $\mathrm{SLR}=1 \mathrm{~m}$. From these studies, assuming unchanged bathymetry in these coral reef environments, SLR has the potential to induce wave setup decreases of a few centimeters up to tens of centimeters or more.

\section{Discussion}

\subsection{Synthesis}

The literature review shows that site-specific knowledge of the importance of each interaction mechanism is very heterogeneous (Fig. 2) with some sites or regions receiving little attention (see, e.g., the West Africa coast) and others subject to many studies (e.g., NW European shelf). In the literature, there are few environments or sites where all the 


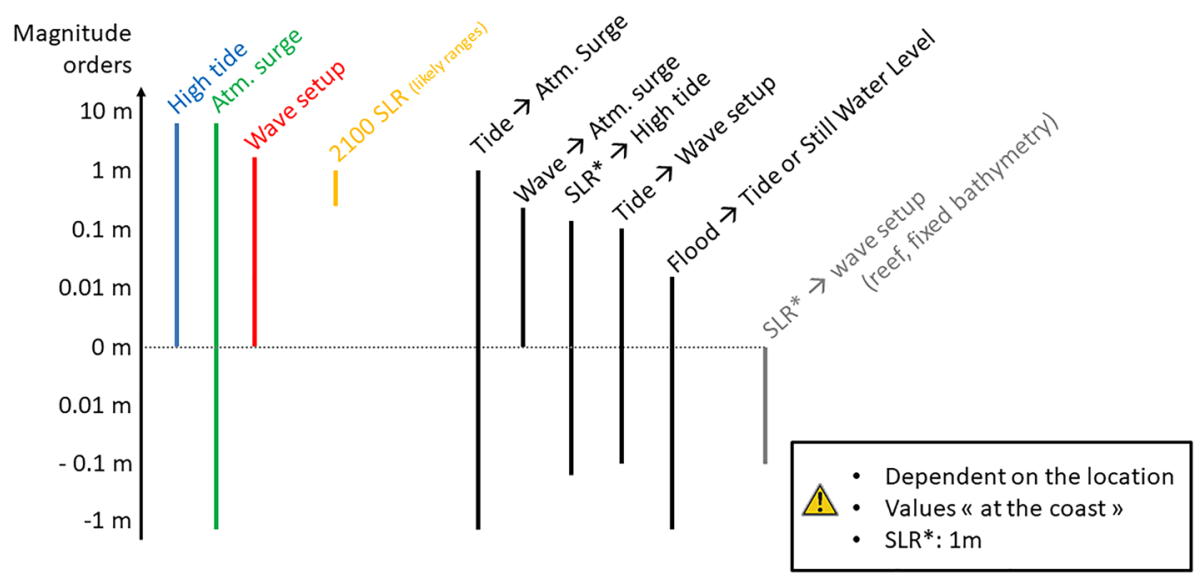

Fig. 6 Orders of magnitude of main water level components (in color) and some of the interactions (in black) investigated in the present paper. The orders of magnitude are based on the publications reviewed in the present paper and on Woodworth et al. (2019). It should be noted that these orders of magnitude are provided 'at the coast' (i.e., at the waterline). This does not exclude larger effect in the nearshore (for instance for tide modulation of wave setup in the surf zone)

interactions investigated here have been quantified separately. However, we can still extract some ranges (in order of magnitude) for some of the interactions (Fig. 6), to compare with the orders of magnitude of the main water level components, keeping in mind that the importance of interactions strongly depends on the location, the amount of SLR and the considered meteorological event.

High tide amplitudes (relative to mean sea level) range from decimetric to metric magnitudes (locally exceeding $8 \mathrm{~m}$ in the Bay of Fundy), but sea level rise can cause significant modifications. Changes in $M 2$ amplitude or MHW changes of several centimeters to more than $10 \mathrm{~cm}$ for SLR scenarios of $\sim 1$ to $2 \mathrm{~m}$ have been obtained from modeling studies. Flooding of previously dry land can also induce tide changes of several centimeters to more than $10 \mathrm{~cm}$ nearshore with potential effects at the basin scale (as in the North Sea for instance). The flood effect is mainly negative (i.e., it reduces the high tide level).

Wave setup ranges between a few to tens of centimeters and up to about $1 \mathrm{~m}$. We cannot, however, exclude that larger wave setup could occur. Tides can modulate wave setup from several centimeters on open beaches to tens of centimeters at inlet or estuary mouths (shoals). Nearshore areas (e.g., open sandy coasts and inlets) are known to have dynamic morphologies on event, seasonal or pluriannual timescales. On longer timescales, under the effect of SLR, the morphology is expected to change significantly such that providing specific estimates of the SLR effect on wave setup is perhaps too ambitious. However, assuming an unchanged bathymetry such as in reef environments, wave setup (at the lagoon scale) is expected to decrease $O(10 \mathrm{~cm})$, while on fixed open beaches, setup is expected to increase.

Atmospheric surges range from a few centimeters to tens of centimeters, reaching a few meters in exceptional cases and up to $10 \mathrm{~m}$ in cyclonic areas. Again, we cannot exclude larger atmospheric storm surges. Tide-surge interactions can lead to surge changes of a few to tens of centimeters and up to almost $1 \mathrm{~m}$. In addition, the wave effect on the sea surface roughness can increase atmospheric surges up to a few tens of centimeters, especially under young sea states. 
In summary, there exist locations where each interaction discussed in the present review can reach values of a few tens of centimeters while some interaction processes can contribute almost $1 \mathrm{~m}$ to coastal water level. These contributions to total water level are far from negligible and must be considered in planning and mitigation efforts. As highlighted above, site-specific knowledge of the importance of each interaction mechanism is heterogeneous. However, the sites discussed here give some indication where the significant interactions are likely to occur. According to the available literature, along the US East coast, the Patagonian coast, the NW European coasts, and in San Francisco Bay and Taiwan Strait, there exists a significant effect of SLR on tide and tide-surge interaction. All these sites are characterized by substantial shallow water areas. This suggests that there should be other shallow areas subject to non-negligible SLR-tide-surge interactions, such as Indonesia, for instance. Along open coasts with narrow continental shelves, the SLR effect on tide, surge and tide-surge interaction is expected to be negligible. Similarly, based on the shallow water equations and the literature review, significant effects from waves on atmospheric storm surges are expected only in shallow water areas. Regarding the effect on tides of letting previously dry areas flood or not, it is not straightforward to identify the potential areas where this will be a significant effect. However, we can still expect significant changes in shallow water areas characterized by low-lying coasts, especially in estuaries or tidal inlets. As a result, the following areas (not exhaustive) appear sensitive to at least one of the interactions investigated in the present paper: Hudson Bay, European continental shelf, straits with significant tidal currents (e.g., Taiwan), the northern coast of Australia, the Patagonian shelf, Gulf of Mexico and San Francisco Bay.

\subsection{Combined Interactions}

The present review focused on a few of the possible interactions and on studies providing results concerning each individual interactions. However, multiple studies address the combined effect of multiple interactions, such as taking into account coincident interactions between tides, atmospheric surges, waves and wave setup (e.g., Brown et al. 2013), mainly at local scales.

At the scale of the US East and Gulf coasts Marsooli and Lin (2018) investigated historical storm tides resulting from tide, atmospheric surge and wave setup and the interactions between these components using a numerical modeling approach, focusing on past tropical cyclones (1988-2015). Model results show that the maximum water level rise due to nonlinear tide-surge interaction in most regions along the US East and Gulf Coasts (especially in Long Island Sound, Delaware Bay, Long Bay and along the western coast of Florida) was relatively large but did not occur at the timing of the peak storm tide. Model results at the location of selected tide gauges showed that the contribution of tide-surge interaction to the peak storm tide was between -25 and $+20 \%$ (from -0.35 to $0.31 \mathrm{~m}$ ). During the most extreme storm events (i.e., tropical cyclones that caused a storm tide larger than $2 \mathrm{~m}$ ), the tide-surge interaction contribution ranged between - 12 and 5\%. Brown et al. (2013) found a similar behavior on the Liverpool Bay, showing that the maximum wave setup occurs at low water, stressing the effect of the banks (or shoals) at the mouth of the estuary.

Several studies quantified the effect of large coastal flooding on the still water level (i.e., on tide and surge, implicitly including the tide effect on surge), mainly at regional or local scales. For instance, Townend and Pethick (2002) showed that the removal of coastal defenses along several English estuaries allowed the flooding of extensive areas and result 
in a water level reduction locally exceeding $1 \mathrm{~m}$. Bertin et al. (2014) and Huguet et al. (2018) showed that the massive flooding associated with Xynthia (February 2010, central part of the Bay of Biscay) induced a still water level decrease ranging from $0.1 \mathrm{~m}$ at the entrance of the estuaries to more than $1.0 \mathrm{~m}$ inside estuaries compared to a situation where the flooding would have been prevented. Note that these two studies revealed that the impact of freshwater discharges was negligible in the case of Xynthia, mostly because freshwater discharges were close to yearly mean values. Different conclusions might be drawn for tropical hurricanes, which are usually associated with heavy rainfall. These findings and the corresponding orders of magnitude have been corroborated in other French estuarine environments (Chaumillon et al. 2017; Waeles et al. 2016).

While there are few studies focusing on the sole effect of SLR on pure atmospheric surges, there are several studies investigating the effect on the still water level or practical storm surge. For instance Arns et al. (2017) show that SLR scenarios of $54 \mathrm{~cm}, 71 \mathrm{~cm}$, and $174 \mathrm{~cm}$ lead to decreases of the practical atmospheric storm surge (still water level minus tide) of $1.8 \%, 2.3 \%$ and $5.1 \%$, on average in the German Bight area. They show that, with SLR and a fixed bathymetry, the modulation of waves by the storm tide should decrease. The observed correlation between waves and storm tides decreases with SLR, such that waves and storm tides become more independent with SLR.

As a last example of studies providing quantitative values on combined interactions, Krien et al. (2017a) investigated the effect of SLR on 100-year surge levels (including atmospheric surge and wave setup) along the coasts of Martinique (Caribbean islands). They show that a $1 \mathrm{~m}$ SLR leads to changes in the 100-year surge levels ranging between -0.3 and $+0.5 \mathrm{~m}$ in areas of coral reef and shelf. Most of the domain (especially between the eastern shoreline and coral reefs) is subject to a decrease (larger water depths induce a decrease in wave setup and wind induced storm surge), while increase is observed in very local low-lying regions where the inundation extent is strongly enhanced by the sea level rise.

\subsection{Implications for Water Level and Flood Projections}

Interactions between the contributions to coastal water level have significant implications for projected changes in the frequency and amplitude of future extreme events, yet most projections neglect the interactions discussed in this paper and consider only linear additions of the relevant processes (Muis et al. 2016; Vitousek et al. 2017; Melet et al. 2018; Vousdoukas et al. 2018). Often, projected SLR is added to current tidal datums with the assumption that a given increment of SLR corresponds to an equivalent increment in the average high tide (i.e., MHW) or some other relevant datum. As discussed above and demonstrated for instance by Pickering et al. (2017), this assumption is not valid in many shelf seas across the global ocean. The obvious implication of the nonlinear relationship between SLR and tidal amplitude is an enhancement or reduction in future water level at high tide. From a planning perspective, however, it is also important to consider how the nonlinear response of tidal amplitude to SLR affects the timing of impacts. Rates of SLR will be on the order of $10 \mathrm{~cm}$ per decade under the plausible scenario that GMSL rises by $1 \mathrm{~m}$ during the twenty-first century. The nonlinear response of tidal amplitude to $1 \mathrm{~m}$ of SLR is also on the order of $\pm 10 \mathrm{~cm}$ in some locations (Pickering et al. 2017). Thus, the effect of tidal amplification on the MHW datum can be roughly equivalent to the effect of \pm 1 decade of SLR. Depending on the sign and magnitude of the tidal amplification at a given location, 
optimal planning horizons may need to be adjusted earlier or later to account for the nonlinear response of tidal amplitude and its effect on the frequency of high-tide flooding.

In addition, changes in mean sea level will cascade through the different interaction mechanisms with the net effect potentially resulting in several tens of centimeters of additional (or reduced) water level at the coast during extreme events (e.g., Arns et al. 2017). SLR will directly affect water levels associated with tides, atmospheric storm surges and wave setup with additional indirect effects on surges through tide-surge interactions. Even excluding the interaction between these processes, a $10 \mathrm{~cm}$ increase in mean sea level corresponds to a doubling of the frequency of former 50-year return total water levels over much of the global ocean, with approximately $25 \mathrm{~cm}$ required for the doubling in areas most affected by storm surge (Vitousek et al. 2017). These mean sea level changes are of the same order of magnitude as the interaction effects (Fig. 6), suggesting that the frequency of the most extreme water level events could increase much more rapidly than currently projected in locations where constructive interactions between processes are strongest.

Explicitly accounting for the interactions between processes in projections of future total water level is not trivial. In practice, a detailed accounting of the interactions requires high-resolution tide, wave, and surge models (including wave setup) with high-quality bathymetry and reasonable estimates of local bottom friction. Indeed, even if in many cases a resolution of few hundred meters is sufficient to capture tide, atmospheric surge and their interaction (see, e.g., Idier et al. 2012; Muller et al. 2014, in which $2 \mathrm{~km}$ resolution models are used), it is not sufficient to capture regional and local wave setups, which, depending on the environment, require resolutions of tens and few meters, respectively, but also highquality bathymetry (see, e.g., Bertin et al. 2015; Pedreros et al. 2018). The quality of the topography (especially on the coastal defenses) is also crucial to account for the flooding effect on coastal water level. As highlighted here and in Sect. 4.4 (penultimate paragraph), there are downscaling challenges, but there are also upscaling issues (indeed, local processes as for instance dissipation by floods or on intertidal areas or tidal bedforms may also affect the regional dynamic). In addition, to account for the uncertainties in the future climate projections, many simulations should be done. Thus, global modeling assessments currently exceed what is computationally feasible, while accurate bathymetric and bottom friction information is not available in many locations.

Given these challenges, a statistical approach should be employed when possible to include process interactions in projections of flood frequency and return periods of extreme events. Probabilistic projections of extreme water levels (e.g., Vousdoukas et al. 2018) offer an opportunity to include statistical representations of process interactions, but this approach has yet to be implemented. Fortunato et al. (2016) proposed a solution to account for tide-surge interactions in extreme value statistics for the coasts of the Iberic Peninsula, although the interactions are not the strongest in this region. To include process interactions in probabilistic projections of extreme water level events, statistical covariance relationships must be established between the processes contributing to total water level. For example, one can envisage a spatially variable covariance relationship between mean sea level and tidal amplitude derived from scenario-based tide modeling studies such as Pickering et al. (2017) or Schindelegger et al. (2018). General covariance relationships between other processes could be estimated by leveraging regional and local modeling frameworks designed for specific local case studies. Exploring physically reasonable parameter spaces in a small number of locations that span general classes of coastal environments (e.g., reef-lined islands, shelf seas, etc.) could provide reasonable estimates of covariance relationships that could be applied more generally to coastal environment classes in a global 
probabilistic framework. Regardless of approach, a high priority must be placed on developing covariance relationships between contributions to total water level in order to provide accurate projections of water level extremes.

\subsection{Limits, Gaps and Remaining Questions}

The values and orders of magnitude provided in the present review should be used with some caution. Indeed, this study is based on a literature review, keeping in mind that some areas or environments have been subject to fewer investigations than others, and that the values are dependent on the considered scenarios (e.g., SLR values) and/or meteorological events. In addition, the review relies on modeling studies (as this is the only way to distinguish every component and contribution), such that even if most of the modeling experiments have been validated with observations, there are still some epistemic uncertainties related either to the water level measurements or the modeling (errors in input data, e.g., bathymetry, atmospheric forcing, etc.; representation or omission of the underlying dominant process). For instance, Apotsos et al. (2007) showed that wave setup estimates based on the depth-integrated approach of Longuet-Higgins and Stewart (1964) can be biased low by a factor of two along the shoreline. While most storm surge modeling systems rely on a similar approach, one can expect that wave setup is not always well represented in 2D models. Also, field measurements in surf zones under storm waves are limited to a very few studies (Guérin et al. 2018; Pedreros et al. 2018). These difficulties highlight an urgent need for detailed field observations of wave setup under storm wave conditions.

Regarding validation of modeled tide changes, Schindelegger et al. (2018) investigated the SLR effect on tides and made a thorough comparison of model results with 45 tide gauge records. Their model reproduces the sign of observed amplitude trends in $80 \%$ of the cases and captures considerable fractions of the absolute $M 2$ variability, specifically for stations in the Gulf of Mexico and the Chesapeake-Delaware Bay system. This result gives strong support to the fact that, in many locations, a significant part of observed tide changes could be attributed to the effect of SLR. Still, discrepancies in models/data remain in several key locations, such as the European Shelf. Indeed, as highlighted by Haigh et al. (2018), many processes can cause changes in tides (sea ice coverage, seabed roughness, ocean stratification, internal tides, etc.), and it remains difficult to associate observed changes in tide over the instrumental period with particular forcing factors. Furthermore, it remains unclear how some of these forcing factors would change with SLR and more 'generally' with the future climate. Finally, while the agreement in local- to regional-scale tidal changes from differing models (e.g., on the NW European Shelf) provides some confidence, it would be of value to conduct further investigations of macro-tidal regions (such as the Bristol Channel) with consideration of interim 'partial recession' or 'flood' scenarios depending on coastal management priorities and sensitivities to the resulting change.

In the present review, we focus on SLR, tide, atmospheric surge, wave and wave setup interactions. However, in estuaries and inlets, when not negligible, the interaction between water level and river discharge should also be considered. Water depth changes are dependent on river discharge $\left(Q_{\mathrm{r}}\right)$ in estuarine locations. An increase in $Q_{\mathrm{r}}$ will increase mean sea level locally, but the increased friction of the incoming tide interacting with the outgoing river discharge will lead to a decrease in tidal amplitude (Devlin et al. 2017). Krien et al. (2017b) performed a high-resolution hindcast of the storm surge and flooding associated with cyclone Sidr (2007) in the head of the Bay of Bengal. They showed that, while 
tide-surge interactions can impact the storm surge by -0.5 to $+0.5 \mathrm{~m}$, accounting for river discharge can also impact storm-induced flooding substantially.

The interactions investigated in the present review exhibit different spatial scales; the wave setup changes induced by tidal water level and currents or SLR occur mainly at a local scale, while tide-surge interactions and SLR effects have local, regional and global scales. Indeed, tide and atmospheric surge dynamics result from global-, regional- and local-scale mechanisms. A few studies have provided maps of the SLR effect on tide at the global scale. First, as much as possible, at least in regions exhibiting a significant effect of SLR on tides, it is recommended to take into account the global-scale changes in the open boundary conditions of regional or local modeling studies (as in Harker et al. 2019, for instance). Second, to the authors' knowledge there is no study at a global scale investigating tide-surge interaction or SLR effect on atmospheric surge (except tide gauge based studies, which provide local information, non-uniformly spread around the world; see, e.g., Arns et al. 2019). Such studies would be very helpful for hindcasts and projections of still water level or for coastal flood hazard assessment by allowing areas sensitive to SLR, tide and atmospheric surge interactions to be identified.

As mentioned above, one of the main issues when focusing on nearshore water level is the temporal evolution of the seabed topography/morphology. Indeed, such changes, especially for sandy beaches exposed to waves, can have a significant effect on the wave setup (at different timescales: event, seasonal, inter-annual to longer term). For instance, Thiébot et al. (2012) and Brivois et al. (2012) show how, depending on the wave and water level characteristics, different morphologies can emerge on doubled sandbar systems, and thus can alter water level at the coast, especially the wave setup. Morphological changes can also alter the tidal dynamics and related water levels. Ferrarin et al. (2015) investigated the effect of morphology changes and MSL on tides in the Venice lagoon over the last 70 years. While tidal amplitudes in the North Adriatic Sea did not change significantly (even if they exhibit some fluctuations), morphological changes that occurred in the lagoon in the last century produced an increase in the amplitude of major tidal constituents (e.g., $M 2$ increase up to about $20 \%$ with respect to the imposed tidal wave). This raises the question of how the sole effect of a changing seabed morphology (related to SLR, wave climate change, or human intervention) compares with the interactions investigated in this review.

\section{Conclusions and Perspectives}

The present paper focused on water level at the coast resulting from the interaction between SLR, tides, atmospheric surge and wave setup. While the discussed mechanisms of interaction were previously known, we provide an overview of quantifications of the interactions based on modeling studies. The largest identified interaction is the tide-surge interaction which can lead to changes in the practical atmospheric surge up to $1 \mathrm{~m}$ or more. SLR with a metric value can induce high tide changes (positive or negative) exceeding $10 \mathrm{~cm}$, while waves can increase the atmospheric storm surge a few centimeters up to tens of centimeters. The flood effect on tide and still water level can induce changes (mainly negative) ranging from a few centimeters up to more than $1 \mathrm{~m}$ in estuaries. The modulation of wave setup by the tide can represent a few centimeters at the shoreline, but can reach tens of centimeters on ebb shoals. The effect of SLR on wave setup is more debatable, but could be positive or negative depending on the nearshore bathymetry and beach slope. 
The review also suggests that these interactions have smaller magnitudes in deeper areas and can thus be considered as negligible in some locations. On the contrary, many studies show significant interactions in shallow water. The sensitive areas we identified include Hudson Bay, European continental shelves, straits with significant tidal currents (e.g., Taiwan), the northern coast of Australia, the Patagonian shelf and the Gulf of Mexico. However, the spatial distribution of studies focusing on these interactions is heterogeneous.

In areas where non-negligible interactions are expected, we suggest these interactions to be taken into account (either by numerical modeling or by statistical methods) in assessments of nearshore water levels and induced coastal flooding. Including interaction mechanisms is especially important when projecting future coastal flooding including SLR.

The present review focused on a subset of the possible interactions, but within the estimation of future water levels, additional complexity arises. Regarding future tide changes, further investigations are needed to better identify if and which phenomena other than the sea level rise could have a significant effect on tides. Finally, the nearshore area is a key zone for tide and surge dissipation, but also wave setup. However, especially under a rising sea level, significant morphological changes are expected in these nearshore areas. The effect of changes in nearshore bathymetry deserves more attention, at least considering scenarios to better characterize the sensitivity of water level to these changes in comparison with changes induced by the interactions discussed in the present paper.

Acknowledgements The authors are grateful to Philip Woodworth and Martin Verlaan for fruitful discussions. This paper arose from the workshop on 'Understanding the Relationship between Coastal Sea Level and Large-Scale Ocean Circulation,' held at the International Space Science Institute (ISSI), Bern, Switzerland on March 5-9, 2018. The authors wish also to thank Anny Cazenave for the initiative of the workshop and associated Special Issue. Contributions to this work from Déborah Idier were funded by BRGM and the ECLISEA project (which is part of ERA4CS, an ERA-NET initiated by JPI Climate with co-funding by the European Union, Grant 690462). Contributions from Xavier Bertin were funded through the Regional Chair Program 'EVEX.' Contributions from Philip Thompson were funded by the NOAA Research Global Ocean Monitoring and Observing Program in support of the University of Hawaii Sea Level Center (NA16NMF4320058).

Open Access This article is distributed under the terms of the Creative Commons Attribution 4.0 International License (http://creativecommons.org/licenses/by/4.0/), which permits unrestricted use, distribution, and reproduction in any medium, provided you give appropriate credit to the original author(s) and the source, provide a link to the Creative Commons license, and indicate if changes were made.

\section{References}

Antony C, Unnikrishnan AS (2013) Observed characteristics of tide-surge interaction along the east coast of India and the head of Bay of Bengal. Estuar Coast Shelf Sci 131:6-11. https://doi.org/10.1016/j. ecss.2013.08.004

Apotsos A, Raubenheimer B, Elgar S, Guza RT, Smith J (2007) Effects of wave rollers and bottom stress on wave setup. J Geophys Res Oceans 112:C02003. https://doi.org/10.1029/2006JC003549

Ardhuin F, Roland A, Dumas F, Bennis A-C, Sentchev A, Forget P, Wolf J, Girard F, Osuna P, Benoit M (2012) Numerical wave modeling in conditions with strong currents: dissipation, refraction, and relative wind. J Phys Oceanogr 42(12):2101-2120. https://doi.org/10.1175/JPO-D-11-0220.1

Arns A, Wahl T, Dangendorf S, Jensen J (2015) The impact of sea level rise on storm surge water levels in the northern part of the German Bight. Coast Eng 96:118-131. https://doi.org/10.1016/j.coastaleng .2014.12.002

Arns A, Wahl T, Dangendorf S, Jensen J, Pattiaratchi C (2017) Sea-level rise induced amplification of coastal protection design heights. Sci Rep 7:40171. https://doi.org/10.1038/srep40171 
Arns A, Wahl T, Wolff C, Vafeidis A, Jensen J (2019) Global estimates of tide surge interaction and its benefits for coastal protection. EGU General Assembly 2019, Geophysical Research Abstracts 21, EGU2019-7307-1

Bennis A-C, Dumas F, Ardhuin F, Blanke B (2012) Mixing parameterization: impacts on rip currents and wave set-up. Ocean Eng 84:213-227. https://doi.org/10.1016/j.oceaneng.2014.04.021

Bertin X, Olabarrieta M (2016) Relevance of infragravity waves in a wave-dominated inlet. J Geophys Res Oceans 121:1-15. https://doi.org/10.1002/2015JC011444

Bertin X, Bruneau N, Breilh J-F, Fortunato AB, Karpytchev M (2012) Importance of wave age and resonance in storm surges: the case Xynthia, Bay of Biscay. Ocean Model 42:16-30. https://doi. org/10.1016/j.ocemod.2011.11.001

Bertin X, Li K, Roland A, Zhang YJ, Breilh JF, Chaumillon E (2014) A modeling-based analysis of the flooding associated with Xynthia, central Bay of Biscay. Coast Eng. https://doi.org/10.1016/j.coast aleng.2014.08.013

Bertin X, Li K, Roland A, Bidlot J-R (2015) The contribution of short-waves in storm surges: two case studies in the Bay of Biscay. Cont Shelf Res 96:1-15. https://doi.org/10.1016/j.csr.2015.01.005

Breilh J-F, Bertin X, Chaumillon E, Giloy N, Sauzeau T (2014) How frequent is storm-induced flooding in the central part of the Bay of Biscay? Glob Planet Change 122:161-175. https://doi.org/10.1016/j. gloplacha.2014.08.013

Brivois O, Idier D, Thiébot J, Castelle B, Le Cozannet G, Calvete D (2012) On the use of linear stability model to characterize the morphological behaviour of a double bar system. Application to Truc Vert beach (France). CR Geosci 344:277-287. https://doi.org/10.1016/j.crte.2012.02.004

Brown JM, Souza AJ, Wolf J (2010) An investigation of recent decadal-scale storm events in the eastern Irish Sea. J Geophys Res 115:C05018. https://doi.org/10.1029/2009JC005662

Brown JM, Bolaños R, Wolf J (2013) The depth-varying response of coastal circulation and water levels to $2 \mathrm{D}$ radiation stress when applied in a coupled wave-tide-surge modelling system during an extreme storm. Coast Eng 82:102-113. https://doi.org/10.1016/j.coastaleng.2013.08.009

Bruun P (1962) Sea level rise as a cause of shore erosion. J Waterw Harb Div 88:117-130

Carless SJ, Green JAM, Pelling HE, Wilmes S-B (2016) Effects of future sea-level rise on tidal processes on the Patagonian Shelf. J Mar Syst 163:113-124. https://doi.org/10.1016/j.jmarsys.2016.07.007

Carrere L, Lyard F, Cancet M, Guillot A, Picot N (2015) FES 2014, a new tidal model—validation results and perspectives for improvements. Geophys Res Abstracts 17:EGU2015-5481-1, EGU General Assembly 2015

Charnock H (1955) Wind stress on a water surface. Q J R Meteor Soc 81:639-640

Chaumillon E, Bertin X, Fortunato AB, Bajo M, Schneider J-L, Dezileau L, Walsh JP, Michelot A, Chauveau E, Créach A, Hénaff A, Sauzeau T, Waeles B, Gervais B, Jan G, Baumann J, Breilh J-F, Pedreros R (2017) Storm-induced marine flooding: lessons from a multidisciplinary approach. Earth Sci Rev 165:151-184. https://doi.org/10.1016/j.earscirev.2016.12.005

Chawla A, Kirby JT (2002) Monochromatic and random wave breaking at blocking points. J Geophys Res Oceans 107:1-19. https://doi.org/10.1029/2001JC001042

Church JA, Clark PU, Cazenave A, Gregory JM, Jevrejeva S, Levermann A, Merrifield MA, Milne GA, Nerem RS, Nunn PD, Payne A, Pfeffer W, Stammer D, Unnikrishnan AS (2013a) Sea-level rise by 2100. Science 342(6165):1445-1445. https://doi.org/10.1126/science.342.6165.1445-a

Church J, Clark P, Cazenave A, Gregory J, Jevrejeva S, Merrifield M, Milne G, Nerem R, Nunn P, Payne A, Pfeffer W, Stammer D, Unnikrishnan AS (2013b) Sea level change, pages 1137-1216. Climate change 2013: the physical science basis. Contribution of working group I to the fifth assessment report of the intergovernmental panel on climate change. Cambridge University Press, Cambridge

Clark PU, Shakun JD, Marcott SA, Mix AC, Eby M, Kulp S, Levermann A, Milne GA, Pfister PL, Santer BD, Schrag DP, Solomon S, Stocker TF, Strauss BH, Weaver AJ, Winkelmann R, Archer D, Bard E, Goldner A, Lambeck K, Pierrehumbert RT, Plattner G-K (2016) Consequences of twenty firstcentury policy for multi-millennial climate and sea-level change. Nat Clim Change 6:360-369. https ://doi.org/10.1038/nclimate2923

Dean RG (1991) Equilibrium beach profiles: characteristics and applications. J Coast Res 7:53-84

Devlin AT, Jay DA, Talke SA, Zaron ED, Pan J, Lin H (2017) Coupling of sea level and tidal range changes, with implications for future water levels. Sci Rep 7:17021. https://doi.org/10.1038/s41598-017-17056 $-\mathrm{Z}$

Dodet G, Bertin X, Bruneau N, Fortunato A, Nahon A, Roland A (2013) Wave-current interactions in a wave-dominated tidal inlet. J Geophys Res Oceans 118:1587-1905. https://doi.org/10.1002/ jgrc.20146

Dodet G, Melet A, Ardhuin F, Bertin X, Idier D, Almar R (2019) The contribution of wind generated waves to coastal sea level changes. Surv Geophys (in review) 
Etala P (2009) Dynamic issues in the SE South America storm surge modeling. Nat Hazards 51:79-95. https://doi.org/10.1007/s11069-009-9390-3

Ferrarin C, Tomasin A, Bajo M, Petrizzo A, Umgiesser G (2015) Tidal changes in a heavily modified coastal wetland. Cont Shelf Res 101:22-33. https://doi.org/10.1016/j.csr.2015.04.002

Flather RA (2001) Storm surges. In: Steele JH, Thorpe SA, Turekian KK (eds) Encyclopedia of Ocean Sciences. Academic, San Diego, pp 2882-2892

Fortunato A, Li K, Bertin X, Rodrigues M, Miguez BM (2016) Determination of extreme sea levels along the Iberian Atlantic coast. Ocean Eng 111:471-482. https://doi.org/10.1016/j.oceaneng.2015.11.031

Fortunato AB, Freire P, Bertin X, Rodrigues M, Liberato MLR, Ferreira J (2017) A numerical study of the February 15, 1941 storm in the Tagus estuary. Cont Shelf Res 144:50-64. https://doi.org/10.1016/j. csr.2017.06.023

Godin G (1993) On tidal resonance. Cont Shelf Res 13(1):89-107. https://doi.org/10.1016/02784343(93)90037-X

Grant WD, Madsen OS (1979) Combined wave and current interaction with a rough bottom. J Geophys Res Oceans 84:1797-1808

Green JAM (2010) Ocean tides and resonance. Ocean Dyn 60:1243-1253. https://doi.org/10.1007/s1023 6-010-0331-1

Guérin T, Bertin X, Coulombier T, de Bakker A (2018) Impacts of wave-induced circulation in the surf zone on wave setup. Ocean Model 123:86-97. https://doi.org/10.1016/j.ocemod.2018.01.006

Guerreiro M, Fortunato AB, Freire P, Rilo A, Taborda R, Freitas MC, Andrade C, Silva T, Rodrigues M, Bertin X, Azevedo A (2015) Evolution of the hydrodynamics of the Tagus estuary (Portugal) in the 21st century. J Integr Coast Zone Manag 15(1):65-80. https://doi.org/10.5894/rgci515

Haigh ID, Green M, Pickering MD, Arbic B, Arns A, Dangendorf S, Hill D, Horsburgh K, Howard T, Idier D, Jay D, Lee S, Müller M, Schindelegger M, Talke S, Wilmes S-B, Woodworth P (2018) The tides they are a-Changin'. Rev Geophys. (Submitted)

Harker A, Green JAM, Schindelegger M (2019) The impact of sea-level rise on tidal characteristics around Australia. Ocean Sci Discuss. https://doi.org/10.5194/os-15-147-2019

Hendershott MC (1972) The effects of solid earth deformation on global ocean tides. Geophys J R Astron Soc 29:389-402

Hendershott MC (1973) Ocean tides. Eos Trans AGU 54(2):76-86. https://doi.org/10.1029/EO054i002p 00076-02

Holleman RC, Stacey MT (2014) Coupling of sea level rise, tidal amplification, and inundation. J Phys Oceanogr. https://doi.org/10.1175/JPO-D-13-0214.1

Horsburgh KJ, Wilson C (2007) Tide-surge interaction and its role in the distribution of surge residuals in the North Sea. J Geophys Res Oceans 112:C08003. https://doi.org/10.1029/2006JC004033

Huguet J-R, Bertin X, Arnaud G (2018) Managed realignment to mitigate storm-induced flooding: a case study in La Faute-sur-mer, France. Coast Eng 134:168-176. https://doi.org/10.1016/j.coast aleng.2017.08.010

Hussain MA, Tajima Y (2017) Numerical investigation of surge-tide interactions in the Bay of Bengal along the Bangladesh coast. Nat Hazards 86(2):669-694. https://doi.org/10.1007/s1106 9-016-2711-4

Idier D, Dumas F, Muller H (2012) Tide-surge interaction in the English channel. Nat Hazard Earth Sys 12:3709-3718. https://doi.org/10.5194/nhess-12-3709-2012

Idier D, Paris F, Le Cozannet G, Boulahya F, Dumas F (2017) Sea-level rise impacts on the tides of the European Shelf. Cont Shelf Res 137:56-71. https://doi.org/10.1016/j.csr.2017.01.007

Johns B, Rao AD, Dube SK, Sinha PC (1985) Numerical modelling of tide-surge interaction in the Bay of Bengal. Phil Trans R Soc Lond A 313:507-535

Jones JE, Davies AM (1998) Storm surge computations for the Irish Sea using a three-dimensional numerical model including wave-current interaction. Cont Shelf Res 18:201-251

Kennedy AB, Westerink JJ, Smith JM, Hope ME, Hartman M, Taflanidis AA, Tanaka S, Westerink H, Cheung KF, Smith T, Hamann M, Minamide M, Ota A, Dawson C (2012) Tropical cyclone inundation potential on the Hawaiian Islands of Oahu and Kauai. Ocean Model 52-53:54-68. https:// doi.org/10.1016/j.ocemod.2012.04.009

Kopp RE, Horton RM, Little CM, Mitrovica JX, Oppenheimer M, Rasmussen DJ, Strauss BH, Tebaldi C (2014) Probabilistic 21st and 22nd century sea-level projections at a global network of tide-gauge sites. Earth Fut 2:383-406. https://doi.org/10.1002/2014EF000239

Krien Y, Dudon B, Roger J, Arnaud G, Zahibo N (2017a) Assessing storm surge hazard and impact of sea level rise in the Lesser Antilles case study of Martinique. Nat Hazard Earth Sys 17:15591571. https://doi.org/10.5194/nhess-17-1559-2017 
Krien Y, Testut L, Islam AKMS, Bertin X, Durand F, Mayet C, Tazkia AR, Becker M, Calmant S, Papa F, Ballu V, Shum CK, Khan ZH (2017b) Towards improved storm surge models in the northern Bay of Bengal. Cont Shelf Res 135:58-73. https://doi.org/10.1016/j.csr.2017.01.014

Kuang C, Liang H, Mao X, Karney B, Gu J, Huang H, Chen W, Song H (2017) Influence of potential future sea-level rise on tides in the China Sea. J Coast Res 33(1):105-117. https://doi.org/10.2112/ JCOASTRES-D-16-00057.1

Longuet-Higgins MS, Stewart RW (1964) Radiation stresses in water waves: a physical discussion, with applications. Deep Sea Res Oceanogr Abstr 11:529-562

Malhadas MS, Leitao PC, Silva A, Neves R (2009) Effect of coastal waves on sea level in Obidos Lagoon, Portugal. Cont Shelf Res 1999:1240-1250. https://doi.org/10.1016/j.csr.2009.02.007

Marsooli R, Lin N (2018) Numerical modeling of historical storm tides and waves and their interactions along the US east and Gulf Coasts. J Geophys Res Oceans 123:3844-3874. https://doi. org/10.1029/2017JC013434

Mastenbroek C, Burgers G, Janssen PAEM (1993) The dynamical coupling of a wave model and a storm surge model through the atmospheric boundary layer. J Phys Oceanogr 23:1856-1866

Melet A, Meyssignac B, Almar R, Le Cozannet G (2018) Under-estimated wave contribution to coastal sea-level rise. Nat Clim change 8(3):234-239. https://doi.org/10.1038/s41558-018-0088-y

Moon I-J, Ginis I, Hara T (2004) Effect of surface waves on Charnock coefficient under tropical cyclones. Geophys Res Lett. https://doi.org/10.1029/2004GL020988

Moon I-J, Kwon JI, Lee J-C, Shim J-S, Kang SK, Oh IS, Kwon SJ (2009) Effect of the surface wind stress parameterization on the storm surge modeling. Ocean Model 29(2):115-127. https://doi. org/10.1016/j.ocemod.2009.03.006

Muis S, Verlaan M, Winsemius HC, Aerts JCJH, Ward PJ (2016) A global reanalysis of storm surges and extreme sea levels. Nat Commun 7(11):969. https://doi.org/10.1038/ncomms11969

Muller H, Pineau-Guillou L, Idier D (2014) Ardhuin F (2014) Atmospheric storm surge modeling methodology along the French (Atlantic and English Channel) coast. Ocean Dyn 64:1671-1692. https://doi. org/10.1007/s10236-014-0771-0

Nicolle A, Karpytchev M, Benoit M (2009) Amplification of the storm surges in shallow waters of the Pertuis Charentais (Bay of Biscay, France). Ocean Dyn 59:921. https://doi.org/10.1007/s1023 6-009-0219-0

Nott J, Green C, Townsend I, Callaghan J (2014) The world record storm surge and the most intense southern hemisphere tropical cyclone: new evidence and modeling. Bull Am Meteor Soc 95:757-765. https ://doi.org/10.1175/BAMS-D-12-00233.1

Palmer M, Howard T, Tinker J, Lowe J, Bricheno L, Calvert D, Edwards T, Gregory J, Harris G, Krijnen J, Pickering M, Roberts C, Wolf J (2018) Maine projections. UKCP18 marine report (Met Office)

Pedreros R, Idier D, Muller H, Lecacheux S, Paris F, Yates-Michelin M, Dumas F, Pineau-Guillou L, Sénéchal N (2018) Relative contribution of wave setup to the storm surge: observations and modeling based analysis in open and protected environments (Truc Vert beach and Tubuai island). In: Shim J-S, Chun I, Lim HS (eds) Proceedings from the international coastal symposium (ICS) 2018 (Busan, Republic of Korea). J Coast Res SI85:1046-1050. Coconut Creek (Florida). ISSN 0749-0208. https:// doi.org/10.2112/SI85-210.1

Pelling HE, Green JAM (2014) Impact of flood defences and sea-level rise on the European Shelf tidal regime. Cont Shelf Res 85:96-105. https://doi.org/10.1016/j.csr.2014.04.011

Pelling HE, Green JAM, Ward SL (2013a) Modelling tides and sea-level rise: to flood or not to flood. Ocean Model 63:21-29. https://doi.org/10.1016/j.ocemod.2012.12.004

Pelling HE, Uehara K, Green JAM (2013b) The impact of rapid coastline changes and sea level rise on the tides in the Bohai Sea, China. J Geophys Res Oceans 118:3462-3472. https://doi.org/10.1002/ jgrc. 20258

Pickering MD, Wells NC, Horsburgh KJ, Green JAM (2012) The impact of future sea-level rise on the European Shelf tides. Cont Shelf Res 35:1-15. https://doi.org/10.1016/j.csr.2011.11.011

Pickering MD, Horsburgh KJ, Blundell JR, Hirschi JJ-M, Nicholls RJ, Verlaan M, Wells NC (2017) The impact of future sea-level rise on the global tides. Cont Shelf Res 142:50-68. https://doi. org/10.1016/j.csr.2017.02.004

Powell MD, Vickery PJ, Reinhold TA (2003) Reduced drag coefficient for high wind speeds in tropical cyclones. Nature 422:279-283. https://doi.org/10.1038/nature01481

Pugh DT (1987) Tides, surges and mean sea-level: a handbook for engineers and scientists. Wiley, Hoboken, pp 472

Quataert E, Storlazzi C, van Rooijen A, Cheriton O, van Dongeren A (2015) The influence of coral reefs and climate change on wave-driven flooding of tropical coastlines. Geophys Res Lett 42:6407-6415. https ://doi.org/10.1002/2015GL064861 
Raubenheimer B, Guza RT, Elgar S (2001) Field observations of wave-driven setdown and setup. J Geophys Res Oceans 106:4629-4638. https://doi.org/10.1029/2000JC000572

Ray RD (2001) Internal tides. In: Steele JH (ed) Encyclopedia of ocean sciences. Academic, Berlin, pp 258-265. https://doi.org/10.1016/B978-012374473-9.00125-9

Ross AC, Najjar RG, Li M, Lee SB, Zhang F, Liu W (2017) Fingerprints of sea level rise on changing tides in the Chesapeake and Delaware Bays. J Geophys Res Oceans 122:8102-8125. https://doi. org/10.1002/2017JC012887

Rusu L, Bernardino M, Guedes Soares C (2011) Modelling the influence of currents on wave propagation at the entrance of the Tagus estuary. Ocean Eng 38(10):1174-1183. https://doi.org/10.1016/j.ocean eng.2011.05.016

Schindelegger M, Green JAM, Wilmes S-B, Haigh ID (2018) Can we model the effect of observed sea level rise on tides? J Geophys Res Oceans. https://doi.org/10.1029/2018JC013959

Smith SD, Banke EG (1975) Variation of the sea surface drag coefficient with windspeed. Q J R Meteorol Soc 101:665-673

Stewart RW (1974) The air-sea momentum exchange. Boundary Layer Meteorol 6:151-167

Storlazzi CD, Elias E, Field ME, Presto MK (2011) Numerical modeling of the impact of sea-level rise on fringing coral reef hydrodynamics and sediment transport. Coral Reefs 30:83-96. https://doi. org/10.1007/s00338-011-0723-9

Taylor GI (1922) Tidal oscillations in gulfs and rectangular basins. Proc Lond Math Soc 20:148-181

Thiébot J, Idier D, Garnier R, Falquès A, Ruessink G (2012) The influence of wave direction on the morphological response of a double sandbar system. Cont Shelf Res 32:71-85. https://doi.org/10.1016/j. csr.2011.10.014

Townend I, Pethick J (2002) Estuarine flooding and managed retreat. Proceedings of "Flood risk in a changing climate". Philos Trans R Soc A 360:1477-1495

Van Dorn WG (1953) Wind stress on a artificial pond. J Mar Res 12:249-276

Vitousek S, Barnard PL, Fletcher CH, Frazer N, Erikson L, Storlazzi CD (2017) Doubling of coastal flooding frequency within decades due to sea-level rise. Sci Rep 7(1):1399. https://doi.org/10.1038/s4159 8-017-01362-7

Vousdoukas MI, Mentaschi L, Voukouvalas E, Verlaan M, Jevrejeva S, Jackson LP, Feyen L (2018) Global probabilistic projections of extreme sea levels show intensification of coastal flood hazard. Nat Commun 9(1):2360. https://doi.org/10.1038/s41467-018-04692-w

Waeles B, Bertin X, Chevaillier D, Breilh J-F, Li K, Le Mauff B (2016) Limitation of high water levels in bays and estuaries during storm flood events. In: Gourbesville P, Cunge JA, Caignaert G (eds) Advances in hydroinformatics, SIMHYDRO, pp 439-449

Wang RQ, Herdman LM, Erikson L, Barnard P, Hummel M, Stacey MT (2017) Interactions of estuarine shoreline infrastructure with multiscale sea level variability. J Geophys Res Oceans 122:9962-9979. https://doi.org/10.1002/2017JC012730

Wilmes S-B (2016) The impact of large-scale sea-level changes on tides in the past, present and future. $\mathrm{PhD}$ thesis, Prifysgol Bangor University

Wolf J (1978) Interaction of tide and surge in a semi-infinite uniform channel, with application to surge propagation down the east coast of Britain. Appl Math Model 2:245-253

Wolf J, Flather RA (2005) Modelling waves and surges during the 1953 storm. Phil Trans R Soc A 363:1359-1375. https://doi.org/10.1098/rsta.2005.1572

Woodworth PL, Melet A, Marcos M, Ray R, Woppelmann G, Sasaki N, Cirano M, Hibbert A, Huthnance JM, Montserrat S (2019) Forcing factors causing sea level changes at the coast. Surv Geophys. https:// doi.org/10.1007/s10712-019-09531-1

Woodworth PL (2010) A survey of recent changes in the main components of the ocean tide. Cont Shelf Res 30:1680-1691. https://doi.org/10.1016/j.csr.2010.07.002

Xie L, Pietrafesa LJ, Wu K (2003) A numerical study of wave-current interaction through surface and bottom stresses: coastal ocean response to hurricane Fran of 1996. J Geophys Res Oceans 108:30493066. https://doi.org/10.1029/2001JC001078

Xu JL, Zhang YH, Cao AZ, Liu Q, Lv XQ (2016) Effects of tide-surge interactions on storm surges along the coast of the Bohai Sea, Yellow Sea, and East China Sea. Sci China Earth Sci 59:1308-1316. https ://doi.org/10.1007/s11430-015-5251-y

Yu X, Pan W, Zheng X, Zhou S, Tao X (2017) Effects of wave-current interaction on storm surge in the Taiwan Strait: insights from Typhoon Morakot. Cont Shelf Res 146:47-57. https://doi.org/10.1016/j. csr.2017.08.009

Zhang MY, Li YS (1996) The synchronous coupling of a third-generation wave model and a two-dimensional storm surge model. Ocean Eng 23(6):533-543. https://doi.org/10.1016/0029-8018(95)00067-4 
Zhang W-Z, Shi F, Hong H-S, Shang S-P, Kirby JT (2010) Tide-surge interaction intensified by the Taiwan Strait. J Geophys Res 115:C06012. https://doi.org/10.1029/2009JC005762

Zhang H, Cheng W, Qiu X, Feng X, Gong W (2017) Tide-surge interaction along the east coast of the Leizhou Peninsula, South China Sea. Cont Shelf Res 146:47-57. https://doi.org/10.1016/j. csr.2017.08.009

Zippel S, Thomson J (2015) Surface wave breaking over sheared currents: observations from the Mouth of the Columbia River. J Geophys Res Oceans 222:3311-3328. https://doi.org/10.1002/2016JC012498

Publisher's Note Springer Nature remains neutral with regard to jurisdictional claims in published maps and institutional affiliations. 